\title{
Putting the Squeeze on Compression Garments: Current Evidence and Recommendations for Future Research: A Systematic Scoping Review
}

\author{
Jonathon Weakley ${ }^{1,2,3}$ (1) James Broatch ${ }^{4} \cdot$ Shane O'Riordan $^{4,5} \cdot$ Matthew Morrison $^{1} \cdot$ Nirav Maniar $^{2,6}$. \\ Shona L. Halson ${ }^{1,2}$
}

Accepted: 12 November 2021 / Published online: 6 December 2021

(c) The Author(s) 2021

\begin{abstract}
Background Compression garments are regularly worn during exercise to improve physical performance, mitigate fatigue responses, and enhance recovery. However, evidence for their efficacy is varied and the methodological approaches and outcome measures used within the scientific literature are diverse.

Objectives The aim of this scoping review is to provide a comprehensive overview of the effects of compression garments on commonly assessed outcome measures in response to exercise, including: performance, biomechanical, neuromuscular, cardiovascular, cardiorespiratory, muscle damage, thermoregulatory, and perceptual responses.

Methods A systematic search of electronic databases (PubMed, SPORTDiscus, Web of Science and CINAHL Complete) was performed from the earliest record to 27 December, 2020.

Results In total, 183 studies were identified for qualitative analysis with the following breakdown: performance and muscle function outcomes: 115 studies (63\%), biomechanical and neuromuscular: 59 (32\%), blood and saliva markers: 85 (46\%), cardiovascular: 76 (42\%), cardiorespiratory: 39 (21\%), thermoregulatory: 19 (10\%) and perceptual: 98 (54\%). Approximately $85 \%$ ( $n=156)$ of studies were published between 2010 and 2020.

Conclusions Evidence is equivocal as to whether garments improve physical performance, with little evidence supporting improvements in kinetic or kinematic outcomes. Compression likely reduces muscle oscillatory properties and has a positive effect on sensorimotor systems. Findings suggest potential increases in arterial blood flow; however, it is unlikely that compression garments meaningfully change metabolic responses, blood pressure, heart rate, and cardiorespiratory measures. Compression garments increase localised skin temperature and may reduce perceptions of muscle soreness and pain following exercise; however, rating of perceived exertion during exercise is likely unchanged. It is unlikely that compression garments negatively influence exercise-related outcomes. Future research should assess wearer belief in compression garments, report pressure ranges at multiple sites as well as garment material, and finally examine individual responses and varying compression coverage areas.
\end{abstract}

\section{Introduction}

The use of compression garments during and following exercise has become increasingly popular over the last three decades. Simply, compression garments provide mechanical pressure to the body, which may have physiological, biomechanical, performance, and perceptual benefits for individuals exercising [1-5]. There has been considerable attention

Jonathon Weakley

Jonathon.weakley@acu.edu.au

Extended author information available on the last page of the article given to these garments for their potential ergogenic effects on performance and recovery, with athletes commonly wearing them during competition or in the hours and days following exercise. However, a wide range of mechanisms for their potential efficacy have been provided [6]. With the growing interest in compression garments, there is still ambiguity concerning their potential benefits, the research methodologies applied, and how practitioners should prescribe their use. Therefore, a scoping review that considers the entire area would provide practitioners and researchers with an overview of the current scientific literature and help support future research. 


\section{Key Points}

In the past decade, there has been substantial growth in the amount of compression garment research. The majority of this research has occurred in non-professional adult male participants.

The evidence is equivocal whether compression garments improve physical performance. Furthermore, a range of measures (e.g. rating of perceived exertion, kinetic and kinematic outputs and cardiorespiratory measures) are likely unchanged with their use. However, muscle oscillatory properties, perceived muscle soreness and localised skin temperature may be affected.

Despite evidence suggesting there is little benefit of wearing compression garments, it is unlikely that they harm performance. Additionally, wearing compression garments during certain situations (e.g. exercising in cold temperatures) may be of benefit.

When completing future research, researchers should measure and report wearer belief, pressure and materials, and individual responses to compression garment use.

The inconsistencies in compression garment and exercise outcomes observed throughout the scientific literature are likely due to a number of methodological reasons [6]. For example, research varies according to when the garments are worn (e.g. during exercise and/or recovery) [7-9], the garment pressure and distribution [10-12], where compression is applied (e.g. upper body [torso and/or arms] vs lower body [knee/thigh/full length]) $[13,14]$, the level of competition at which the athlete/participant competes $[12,15$, $16]$, the type of exercise performed [7, 15], and the athlete's belief in the product [2, 17]. Furthermore, considerations such as garment pressure have been estimated to be reported in only one third of the literature to date [6]. This suggests that important methodological information that may influence outcomes is often overlooked. Additionally, while some high-quality reviews have been conducted in the area, they typically have a narrow focus (e.g. high-intensity exercise [18], running performance and recovery [19], recovery from exercise-induced muscle damage $[20,21]$ or central haemodynamics [1]). Therefore, it is often outside the scope of these reviews to provide an overview of the wider knowledge base of compression garments and exercise and present recommendations for the improvement of future research. Thus, a comprehensive overview of the effects of compression garments and commonly assessed outcome measures (i.e. performance, biomechanical and neuromuscular, cardiovascular, cardiorespiratory, muscle damage, thermoregulatory, and perceptual) relevant to athlete performance will support researchers and practitioners by providing potential benefits and recommendations for use. Additionally, by completing a systematic scoping review, the compression garment and exercise literature can be assessed as a whole, which can provide greater context.

While there has been substantial growth in compression garment use during and following exercise, there is uncertainty regarding their effects [18, 22]. Furthermore, the broad application of their use has caused ambiguity in the literature. Therefore, it is important to provide both researchers and practitioners with an overview of the effects across all relevant performance domains, current evidence base and associated outcome measures, and recommendations for future research. Considering these points, the aims of this scoping review are to (1) conduct a systematic search of the published literature and describe the effects of compression garments on responses to exercise; (2) provide a summary of the research outcomes and variables investigated during compression garment research; (3) describe the characteristics of the research and identify gaps in the literature; and (4) provide recommendations for future compression garment research.

\section{Methods}

\subsection{Design and Search Strategy}

A systematic scoping review was carried out in accordance with the Preferred Reporting Items for Systematic reviews and Meta-analyses extension for Scoping Reviews (PRISMA-ScR) [23] and was registered with the Open Science Framework (registration: osf.io/p75×8). A systematic search of electronic databases (PubMed, SPORTDiscus, Web of Science and CINAHL Complete) was performed from the earliest record to 1 June, 2020. An updated search of the literature was completed on 27 December, 2020. All study designs were included. The search strategy is shown in Table 1. Reference lists of selected articles were manually searched for other potentially eligible papers. Once all articles were found, to support dissemination of findings similar to other systematic scoping reviews, outcome variables from all studies were separated into topics.

\subsection{Study Selection}

Following the removal of duplicates, search results were screened independently by two researchers (JW and MM) against the eligibility criteria. Disagreements were resolved through discussion or via a third researcher (SH). Articles that could not be eliminated by the title or abstract were retrieved and evaluated for inclusion via a full-text review. The titles and authors were not masked to the reviewers. 
Studies were eligible for inclusion if they investigated the use of compression garments in able-bodied individuals during exercise or recovery from physical exercise. Additionally, studies were included if they investigated the use of compression garments during activities that related to exercise (e.g. landing, jumping). Only original research investigations in English that were published in peer-reviewed journals were included. Studies were excluded from the review if they did not investigate the effects of compression garments in relation to exercise, or if they investigated the effects of a 'brace' for posture or rehabilitation purposes. For example, Cole et al. [24] investigated whether a scapular stabilization brace acutely alters posture and scapular muscle activity in healthy overhead athletes. While these studies do investigate garments that provide compression, stabilisation braces have a distinctly different purpose to commonly used compression garments. Additionally, studies that did not directly investigate the effects of compression garments (e.g. compression garments were worn during exercise but not investigated) were excluded. Review articles and conference proceedings were excluded. Finally, when authors could not be contacted to retrieve a full text of the article, the study was excluded.

\subsection{Data Extraction}

Following the screening of articles and extraction of information, the authors discussed the overarching themes and topics covered within the compression garment literature. Outcomes from each study were then categorised into topics, similar to previous scoping reviews in sport science [25, 26]. In the current review, these topics were: performance and muscle function, biomechanical and neuromuscular, blood and saliva markers, cardiorespiratory, cardiovascular and haemodynamics, thermoregulatory, and perceptual responses. If an investigation had outcome measures that branched across multiple areas, this study was placed into multiple tables to support the direct comparison of the outcome. It should be noted that if an outcome measure was assessed but was only used to describe participant characteristics rather than used as an outcome of the intervention (e.g.
$V \mathrm{O}_{2 \max }$ of participants in each group $\left.[14,27]\right)$, it was not included in the corresponding table and section. The general characteristics (i.e. year of publication, geography, cohort investigated, sample size, compression garment pressure) of each study were extracted. Data relating to the participants' characteristics (i.e. sex and age), the aim, outcome measures and key findings of each study relating to the purpose of this review were also retrieved. Outcome measures were converted into comparable units where appropriate (e.g. stature converted from $\mathrm{m}$ to $\mathrm{cm}$ ).

\subsection{Data Synthesis}

As the aims of a scoping review are to (1) demonstrate the extent, range and nature of the literature on a topic and (2) summarise the findings of the topic [23], no analysis was carried out. Study characteristics, key outcomes and data are summarised with data presented as mean \pm standard deviation unless otherwise stated.

\section{Results}

\subsection{Search and Selection of Studies}

The literature search identified 974 articles, with five studies identified through a manual search of article reference lists. Following the removal of duplicates and screening of abstracts, 645 full-text articles were assessed for eligibility, with 183 articles included in the qualitative synthesis. The flow of articles through identification to final inclusion is shown in Fig. 1.

\subsection{General Study Characteristics}

\subsubsection{Publication Year and Compression Garment Topics}

Figure 2 demonstrates the substantial growth in studies over recent years, with $\sim 85 \%(n=156)$ of studies published

Table 1 Search terms used in the search strategy

\begin{tabular}{lll}
\hline Term 1 & Term 2 & Term 3 \\
\hline $\begin{array}{ll}\text { Compression Garments OR Compression Stocking } \\
\text { OR Compression Tights }\end{array}$ & Exercise OR Recovery OR Sport & $\begin{array}{c}\text { Muscle Damage OR Perceptual Responses OR Per- } \\
\text { ceived Fatigue OR RPE OR Perceived Recovery }\end{array}$ \\
& & $\begin{array}{l}\text { OR Muscle Soreness OR Blood Flow OR Biome- } \\
\text { chanics OR Kinematics OR Muscle Oscillation }\end{array}$ \\
& & OR Injury OR Proprioception OR Cardiovascular \\
& & OR Temperature OR Strength OR Power OR \\
& & Travel OR Venous Thromboembolism OR VTE \\
& & OR Perfusion OR Vibration OR Fatigue OR Joint \\
& Position \\
\hline
\end{tabular}


between 2010 and 2020. The earliest study that investigated compression garment use and physical exercise was from 1987 [28], while all other studies were from 1995 onwards.

From the 183 studies included in the review, performance and muscle function outcomes were assessed in 114 studies (62\%), biomechanical and neuromuscular outcomes were assessed in 59 (32\%), blood and saliva markers were assessed in $85(46 \%)$, cardiovascular outcomes were assessed in $76(42 \%)$, cardiorespiratory outcomes were assessed in $39(21 \%)$, muscle damage and swelling in $25(14 \%)$, thermoregulatory outcomes were assessed in $19(10 \%)$, and perceptual outcomes were assessed in 98 (54\%). This demonstrates the substantial variance across the domains of interest within the compression garment literature. To illustrate the broad research aims and outcomes, a category breakdown by decade can be found in Table 2 . Additionally, significant positive/negative or conflicting findings to commonly used outcome measures (i.e. outcome measures that were used 10 or more times) are presented in Fig. 3. For ease of interpretation, measures that use similar methodology (e.g. gas analysis outcomes) or imply similar outcomes (e.g. change in thickness and swelling) have been grouped together.

\subsubsection{Geography of Studies}

Of the 183 articles within this review, researchers from Australia have published the greatest number $(n=34)$, followed by the USA $(n=26)$, Spain $(n=18)$, the UK $(n=17)$, France $(n=15)$, Japan $(n=14)$, New Zealand $(n=12)$, Germany $(n=11)$, Canada $(n=8)$, Brazil $(n=7)$, China $(n=5)$, South Korea $(n=4)$, Sweden $(n=3)$, Czech Republic and Italy $(n=2)$, and Lithuania, Slovenia, South Africa, Switzerland, and Turkey (all $n=1$ ). Figure 4 provides a graphical illustration of the articles by country.

\subsubsection{Cohorts Investigated}

The majority of studies within this review investigated participants who were non-professional athletes $(n=175,96 \%)$,
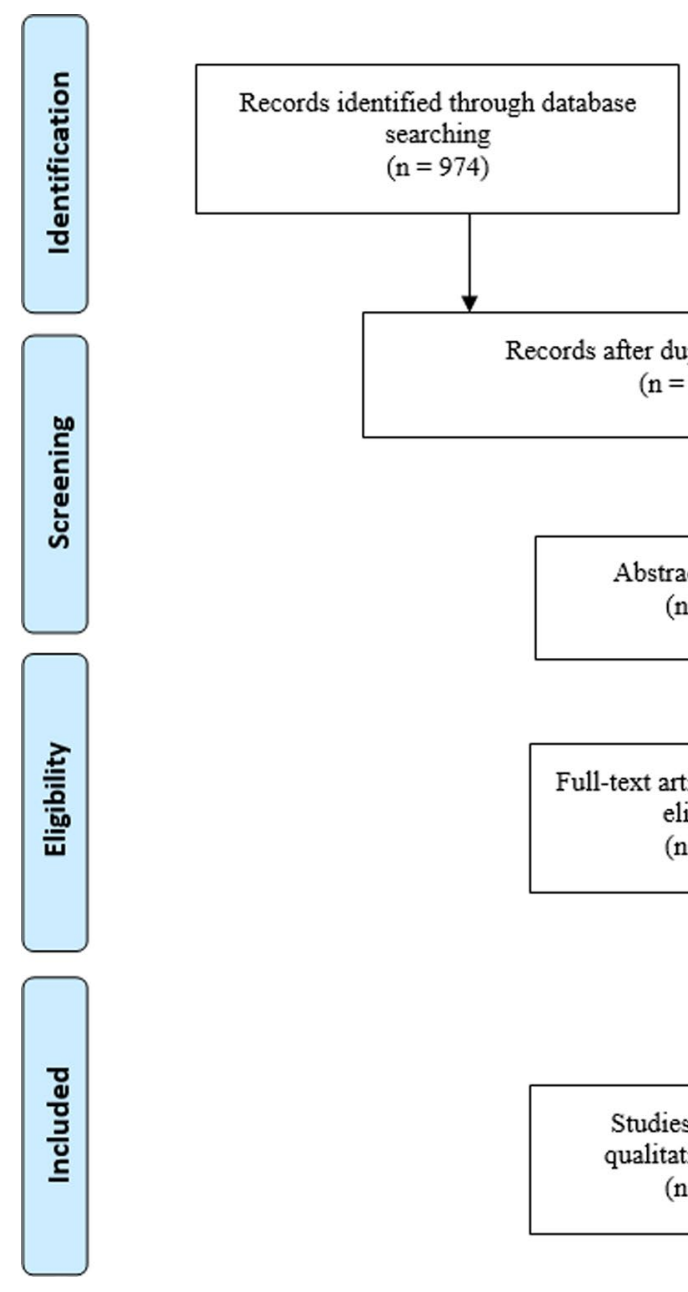

Records after duplicates removed $(\mathrm{n}=645)$

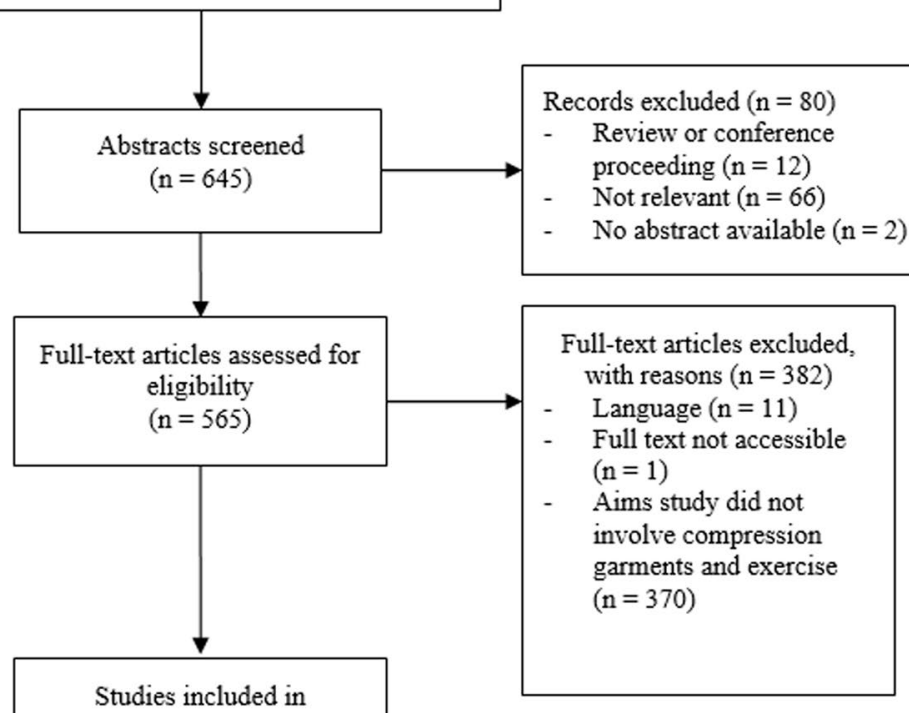

qualitative synthesis ( $\mathrm{n}=183$ )

Fig. 1 Flow of selection process for eligible studies for inclusion 


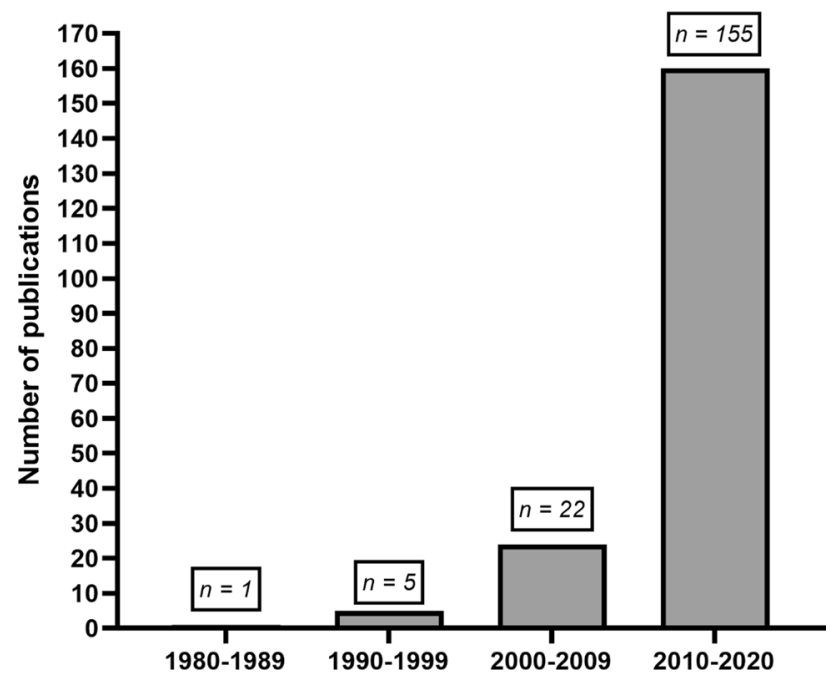

Fig. 2 Number of articles by decade of compression garment and exercise research from earliest records until December 2020

while professional athletes (i.e. an athlete who earns their full time wage through their sport) were used in $n=8(4 \%)$ [29-36]. Of the 183 studies included, 51 investigated mixedsex cohorts, 110 investigated male participants only, and only 14 investigated female participants exclusively. Furthermore, eight studies did not state the sex of the participants [2, 58, 62, 87, 93, 102, 130, 188]. Finally, 167 studies involved adults with a mean reported age between 20 and 64 years, two studies investigated 'older adults' (i.e. participants with a mean age $>65$ years), 11 studies investigated adolescents (i.e. participants with a mean age $<20$ years) [13, 37-46], two studies investigated adult and adolescent cohorts $[33,47]$, and a single study did not provide the age of the participants included [48].

\subsubsection{Compression Garment Types}

The coverage areas of compression garments used in exercise literature are presented in Fig. 5. With multiple garments within the same study, the effects of compression on the lower limbs have been the most investigated $(n=175$, $81 \%)$. Furthermore, upper body compression garments were examined in 19 (9\%) studies, with full-body compression garments investigated also in $19(9 \%)$ studies.

\section{Discussion}

The aims of this study were to (1) conduct a systematic search of the published literature considering the effects of compression garments and exercise; (2) provide a summary of the research outcomes and variables investigated during compression garment research; (3) describe the characteristics of the research and identify gaps; and (4) provide recommendations for the improvement of future compression garment research. From the 183 studies published, outcome measures have been categorised into performance and muscle function, biomechanical and neuromuscular, blood markers, cardiovascular and haemodynamic, cardiorespiratory, muscle swelling and damage, thermoregulatory, and perceptual measures. Findings throughout the literature are conflicting, with compression garments predominantly causing trivial or small beneficial effects during or following exercise (Fig. 6). However, it is unlikely that compression garments negatively influence exercise-related outcomes. Evidence is equivocal as to whether garments improve physical performance, with little evidence supporting improvements in kinetic or kinematic outcomes. However, compression likely reduces muscle oscillatory properties and has a

Table 2 Number of articles that had output measures that related to the eight topics identified within the compression garment and exercise literature

\begin{tabular}{|c|c|c|c|c|c|}
\hline \multirow[t]{3}{*}{ Research topic } & \multicolumn{5}{|c|}{ Year group published } \\
\hline & $<1990$ & $1990-9$ & $2000-9$ & 2010-December 2020 & Total \\
\hline & $\begin{array}{l}\text { Number of inves- } \\
\text { tigations }\end{array}$ & $\begin{array}{l}\text { Number of inves- } \\
\text { tigations }\end{array}$ & $\begin{array}{l}\text { Number of inves- } \\
\text { tigations }\end{array}$ & Number of investigations & $\begin{array}{l}\text { Number of } \\
\text { investigations }\end{array}$ \\
\hline Performance and muscle function & 1 & 4 & 17 & 93 & 115 \\
\hline Biomechanical and neuromuscular & - & 3 & 8 & 48 & 59 \\
\hline Blood and saliva markers & 1 & - & 13 & 71 & 85 \\
\hline Cardiovascular and haemodynamic & - & - & 8 & 66 & 74 \\
\hline Cardiorespiratory & 1 & - & 4 & 32 & 37 \\
\hline Muscle damage and swelling & - & 1 & 5 & 19 & 25 \\
\hline Thermoregulation & - & - & 4 & 15 & 19 \\
\hline Perceptual & - & 2 & 13 & 84 & 99 \\
\hline
\end{tabular}

If a manuscript had multiple measures within the same category, this was still counted as a single article. Additionally, an article could have multiple outcome measures (e.g. body temperature and $V_{2} \mathrm{O}_{2 \max }$ ) 

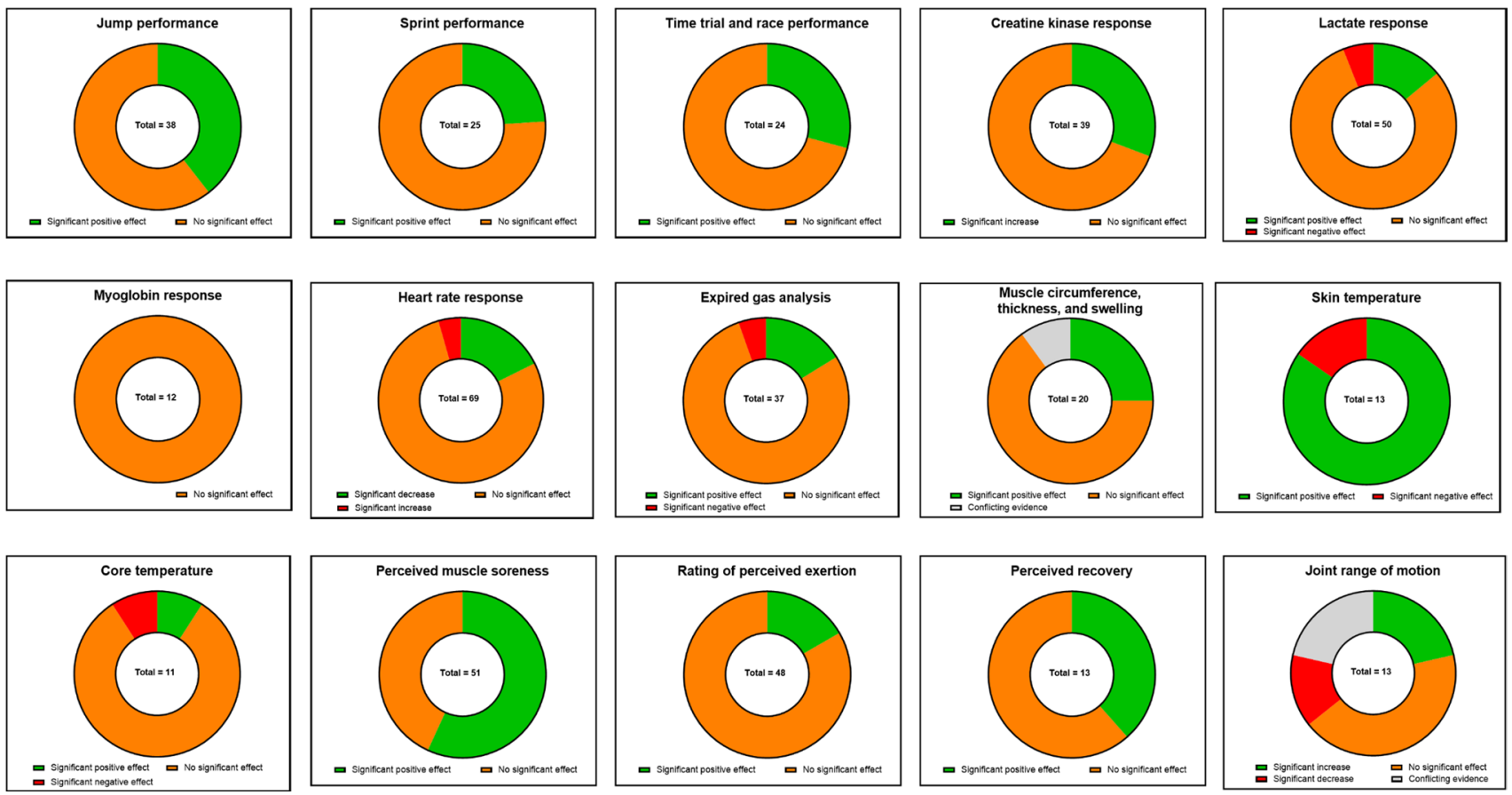

Fig. 3 Commonly used outcome measures and reported significant, non-significant, and conflicting findings

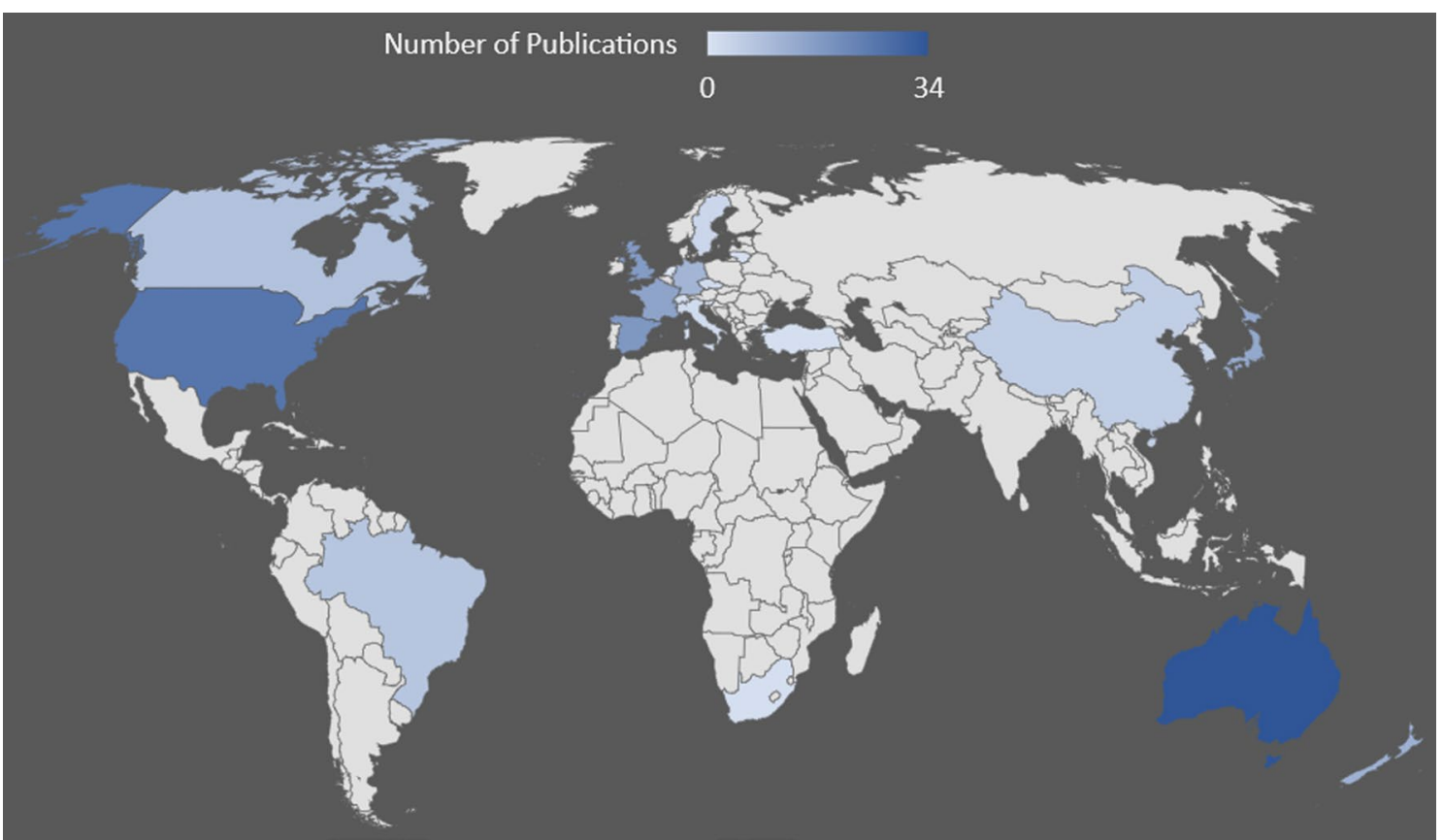

Fig. 4 Heat map of articles published by each country. Articles are attributed to the first affiliation of the first author

positive effect on sensorimotor systems, which may explain the reported beneficial effects on joint proprioception and repositioning sense. Further, potential increases in arterial blood flow may occur. Alternatively, it is unlikely that compression garments meaningfully alter metabolic responses, while blood pressure, heart rate, and cardiorespiratory measures are largely unchanged with their use. Compression garments do increase localised skin temperature and can reduce perceptions of muscle soreness and pain following exercise. However, during exercise, rating of perceived 
Fig. 5 Coverage area of compression garments investigated within the compression garment and exercise literature

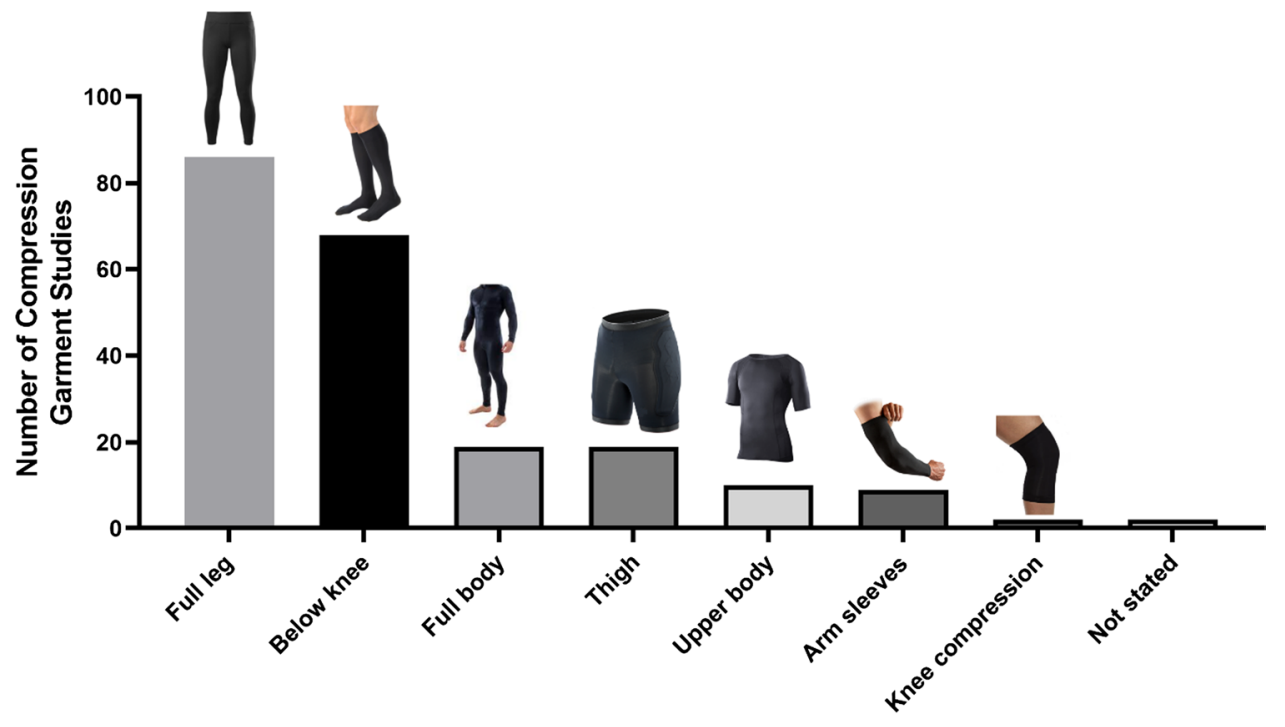

Type of Compression Garment exertion (RPE) is likely unchanged. Globally, these findings suggest that compression garments may have ergogenic benefits in specific settings/circumstances, although practitioners should carefully consider their implementation. Furthermore, it is highly unlikely that compression garments have a detrimental effect on exercise and recovery, suggesting that the potential ergogenic benefits outweigh any associated risks.

\subsection{Performance and Muscle Function}

One-hundred and fifteen studies investigated the effects of compression garments on exercise performance and/or muscle function outcomes (Table S1 of the Electronic Supplementary Material [ESM]). The most common measures investigated were jump $(36 \%, n=41)$, sprint $(22 \%, n=25)$ and time trial $(21 \%, n=24)$ performance. A smaller portion of studies investigated performance metrics including agility $(8 \%, n=9)$, time to exhaustion $(6 \%, n=7)$, incremental exercise test performance $(6 \%, n=7)$, and distance travelled and speed $(4 \%, n=5)$. In addition, six studies investigated sports-specific performance metrics $[2,15$, $31,40,49,50]$. A large number of studies $(40 \%, n=46)$ investigated the effects of compression on metrics related to muscle function, including isometric strength [4, 11, 27, $34,45,51-73]$, isokinetic strength at various contraction speeds [40, 41, 54, 74-87], repetition maximum testing [3, 66, 78, 88, 89], and ballistic movements [40, 57, 87, $90,91]$.

The vast majority of studies reported no ergogenic effect of compression on jump [7, 10, 29, 33, 34, 38, 44, 51, 56, $64,65,70,71,79,80,88-90,92-98]$, time trial/race [36, 56, 95, 99-112], sprint [10, 34, 38-40, 44, 50, 70, 71, 87-89, 92, 96, 97, 113-116], or agility [10, 38, 44, 88] performance.
Nonetheless, there were a number of studies reporting beneficial effects on jump $[3,27,31,39,69,73,85,86,91$, 103, 117-122], time trial/race [5, 17, 72, 123-126], sprint [22, 73, 126-129], and agility [73, 130, 131] performance. A similar pattern was identified with time to exhaustion/ fatigue, as compression is reported to improve [8, 132] or have no effect $[9,12,36,133,134]$ on time to fatigue. Incremental exercise test performance was generally improved when wearing compression garments [28, 100, 131, 135]; however, compression was also reported to have no effect [97] or diminish [47] incremental exercise test performance, highlighting the uncertainty of the effect of compression garments on incremental exercise performance. Compression was reported to improve running speed and distance travelled during netball [92] and team-sport [136] specific circuits, but have no effect on triathlon discipline speed [93] or distance travelled during a simulated soccer match [98]. When investigating sport-specific performance metrics, compression improved tennis shot rate and accuracy [31], but had no effect on throwing [50], kayaking [49], crosscountry ski ergometer double-poling [15], or rugby scrum power [40] performance.

The most commonly used markers of muscle function were isometric $[4,11,27,34,45,51-71]$ and isokinetic [40, 41, 54, 74-87] muscle strength. Despite this, the effects of compression on these strength markers are unclear, as a large number of studies reported either a beneficial effect [4, 27, $34,41,45,66-73,82-86]$ or no effect $[11,40,51-65,74-81$, 87]. Research investigating the effects of compression on ballistic movements is scarce, with reports of a beneficial effect on bench throw [90], but no effect on bench press barbell velocity [57] or plyometric bounds [87]. Similarly, compression has been reported to have a beneficial effect [3, $66]$, or no effect $[78,88,89]$, on repetition maximum testing. 


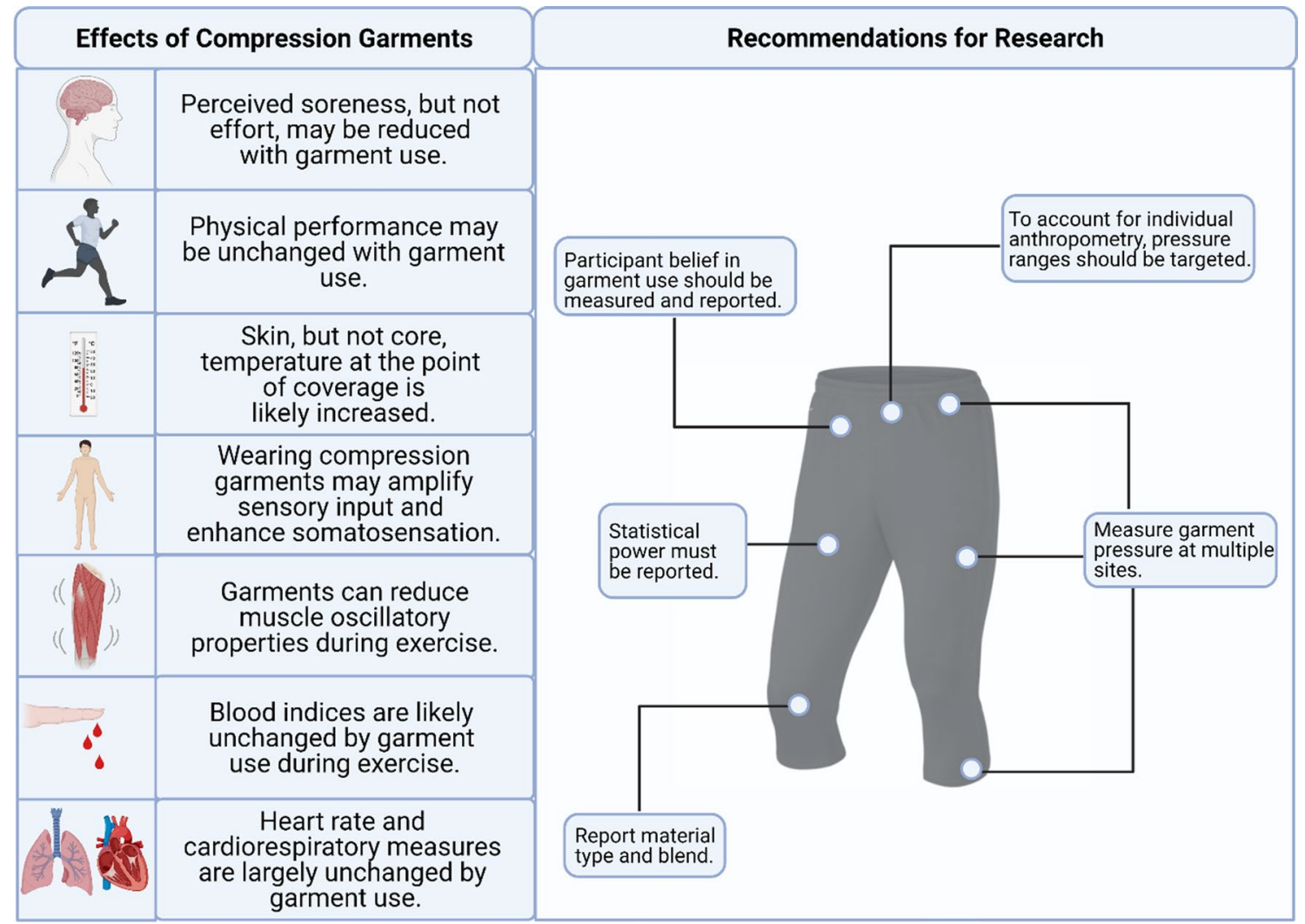

Fig. 6 Research recommendations and a summary of key findings relating to the use of compression garments

Of the 115 studies identified, only one study reported a detrimental effect of compression on performance [47]. Considering this represents a very small percentage $(\sim 1 \%)$ of studies across a wide range of performance metrics, these findings suggest it is highly unlikely that wearing compression garments will negatively influence performance and/or muscle function. Additionally, it may improve performance in certain situations. However, considering the large heterogeneity in performance outcomes between studies, future research may wish to consider adopting 'universal' performance metrics (e.g. muscle strength) that are consistently implemented across studies to help delineate the true effects of compression on performance and muscle function. Furthermore, there is a continued need to identify when compression garments may be of the greatest benefit. Regardless, the potential ergogenic benefit of wearing compression garments far outweigh the risks of a potentially detrimental effect concerning performance and/or muscle function.

\subsection{Biomechanical and Neuromuscular Outcomes}

Fifty-nine studies investigated the effects of compression garments on biomechanical and neuromuscular outcomes (Table S2 of the ESM). Studies used a range of participants from recreationally active $[53,118,137-144]$ to elite-level athletes $[39,51,145,146]$. A large portion of these studies $(49 \%, n=29)$ investigated the effects of compression garments on various kinematic variables including gait [52, $95,104,127,132,145,147]$ and jumping technique [46, $48,118,137], \mathrm{limb} / \mathrm{muscle}$ oscillatory patterns $[39,48,54$, $121,143,148]$, range of motion $[39,42,46,77,84,88,149$, $150]$, and joint angles $[16,46,48,51,118,127,141,147$, 151-153]. Thirteen studies investigated the effects of wearing compression garments on kinetic variables including ground reaction forces during landing [39, 48, 55, 93, 137, $140,145,154]$, leg spring stiffness [104, 137, 145], joint power [132, 147], and joint moments [46, 118, 147]. Neuromuscular parameters were investigated in 33 studies, which comprised predominantly outcomes relating to muscle activation patterns as measured by surface electromyography $(n=20,34 \%)[54,55,58-60,63,68,75,76,82,127,140$, $142,143,146-148,152,155,156]$. Additionally, studies have investigated the effects of compression garments on joint proprioception $[4,53,121,144,149,157,158]$, balance and postural control [138, 140], stability and lower body joint alignment [16], potentiated recruitment patterns and M-wave characteristics using electrical stimulation $(n=5$, $8 \%)[59,87,159,160]$, reaction time [73], skeletal muscle metabolic state during exercise [161] and movement-related cortical patterns via electroencephalography [130]. 
The large majority of studies investigating kinematic outcomes relating to gait (i.e. step length, step frequency, center of gravity, and/or ground contact time) or jumping (i.e. joint angular velocity, flight/loading/contact durations, and/or vertical displacement of the center of mass) reported no effect of compression garments [52, 70, 95, 104, 132, 137, 145, $147,152]$. Only four studies reported beneficial effects of compression on kinematic outcomes, including increased step length [127], decreased contact time/increased aerial time [104], and reduced tibial acceleration [152] during running, as well as improved kicking kinematics in football [42]. Joint range of motion appears to be largely unchanged when compression garments are worn $[16,39,42,46,77$, $88,147,149,150]$; however, some studies have also reported increases $[48,83,84]$ and decreases $[39,46,48,149,153]$ in joint range of motion. Multiple studies have reported beneficial effects of compression on joint angles during exercise [51, 118, 127, 141], which have been hypothesized to reduce the risk of injury during landing [118, 127, 141]. However, considering compression garments have also been reported to have no effect on joint angles during exercise [16, 46, $118,147]$, future research to delineate these differences is warranted. Compression is consistently reported to reduce muscle oscillatory properties during exercise $[39,51,121$, 143, 148]; however, one study has reported compression to have no effect on joint oscillatory properties during drop jumps [48]. Evidence to support the alteration of kinetics with compression is limited, with a large majority of studies showing no effect on ground reaction forces during landing [48, 55, 93, 137, 140, 145], leg stiffness [137, 145], joint power [132, 147], or joint moments [46, 118]. However, some studies have reported beneficial effects of compression to decrease impact force on landing [39], increase force on landing in anterior-cruciate ligament recovery (indicating an increased reliance on the knee) [154], increased leg stiffness [104], and beneficial effects on joint moments during landing [48] and running [147].

A large number of studies reported compression to reduce muscle activation during different contraction/exercise models [54, 55, 75, 76, 142, 143, 148, 155], which has previously been associated with improved contraction efficiency and movement economy [54, 142]. However, a number of studies also reported no effect [58-60, 63, 68, 140, 146, 147, 156] or an increase $[82,127]$ in muscle activation with compression, highlighting the need for more research in this area. Compression was also reported to improve the filtering of 'non-specific' sensory information [155], which may help to explain the compression-induced reported improvements in joint proprioception and repositioning sense [53, 121, $144,149,157,158]$, as well as balance and postural sway $[16,138]$. There is also evidence to suggest that compression garments positively influence potentiated muscle fiber recruitment $[52,159]$ and movement-related cortical patterns [130]; however, research in this area is scarce.

\subsection{Blood and Salivary Outcomes}

Eighty-five studies investigated the effects of compression garments on blood and saliva measures (Table S3 of the ESM). The most common measures investigated were lactate $(n=49,58 \%)$, creatine kinase $(n=39,46 \%)$, inflammation (e.g. c-reactive protein, interleukins, tumour necrosis factor- $\alpha ; n=14,16 \%)$, myoglobin $(n=13,15 \%)$ and lactate dehydrogenase $(n=7,8 \%)$. Other frequent blood markers assessed included glucose $(n=5,6 \%)$, blood $\mathrm{pH}(n=6,7 \%)$, oxygen saturation of haemoglobin $(n=5,6 \%)$, markers of coagulation and fibrinolysis $(n=4,5 \%)$ and partial pressure of oxygen $(n=3,4 \%)$.

A large number of studies $(n=40)$ reported compression to have no effect on lactate, $[7,13,17,22,31,35,36,40$, $41,47,49,50,56,57,61,63,64,87,89,92,94,100,103$, 108-110, 114-116, 119, 120, 123, 126, 127, 129, 132, 133, $135,136,162]$, while seven studies $[5,15,28,124,163-165]$ have reported positive effects of compression (i.e. reduced blood lactate concentration), and three studies [165-167] have reported negative effects. A similar pattern was identified in blood markers used to assess muscle damage. Creatine kinase was largely not influenced by compression, with 27 studies [5, 7, 11, 27, 30, 33, 40, 44, 61, 67, 69, 74, 79, $85-89,93-95,119,120,126,150,168,169]$ reporting no effect, and only 12 studies [32, 38, 50, 65, 71-73, 84, 90, 96, $97,170]$ reporting positive effects. Similarly, 12 studies [5, $7,44,64,66,69,86,88,89,93,95,119]$ reported no effect of compression on myoglobin, and three studies [64, 73, 170] reported a positive effect. Lactate dehydrogenase was not influenced by compression in five studies $[11,38,84,95$, $168]$, while two studies $[90,97]$ reported positive effects. Of the 14 studies investigating blood markers of inflammation, 13 studies [11, 27, 43, 61, 64, 66, 67, 69, 87, 94, 96, 120, 168] reported no effect of compression, and only one study [119] reported a positive effect on interleukin-6. No studies reported negative effects of compression on blood markers of muscle damage and inflammation.

A small number of studies investigated other blood markers including glucose $[64,89,93,119,120]$, blood $\mathrm{pH}[15$, $22,50,87,164,171]$, oxygen saturation of haemoglobin [12, $15,50,93,167]$, and partial pressure of oxygen $[12,15,50]$, with no effect of compression reported, with the exception of a positive effect in one study measuring oxygen saturation of haemoglobin [167]. For markers of coagulation and fibrinolysis two studies reported no effect $[122,169]$, and one study [170] reported a positive effect on thrombin-antithrombin complex and plasminogen activator inhibitor with compression. However, one study [172] reported a negative effect of compression on d-dimer. Finally, there is evidence to suggest 
compression garments positively influence blood markers of glutamic oxalacetic transaminase [97], glutamic-pyruvic transaminase [97], fatty-acid binding protein [112] and biological antioxidant potential [162], and salivary cortisol [37]. However, compression garments appear to have little effect on a range of other blood and salivary markers [30, $43,66,73,90,93,95]$. Future research should aim to identify the influence of when compression is applied (during or post-exercise), and the duration of use on blood and salivary markers. In addition, further research that investigates the effects of compression on markers of coagulation and fibrinolysis during travel in athletes may be beneficial [171].

\subsection{Cardiovascular and Haemodynamic Outcomes}

The results from the 74 studies reporting cardiovascular and haemodynamic measures are provided in Table $\mathrm{S} 4$ of the ESM. The most common central haemodynamic measures investigated were heart rate $(n=68,91 \%)$, blood pressure $(n=9,12 \%)$, cardiac output $(n=5,7 \%)$, stroke volume $(n=4,5 \%)$, and mean arterial pressure $(n=4,5 \%)$. Additionally, studies have investigated the effects of compression on heart rate variability $[13,173,174]$, total peripheral resistance [106, 173], electrocardiography [165, 175], baroreflex sensitivity [173] and total vascular conductance [176]. Peripheral haemodynamic measures assessed while wearing compression garments included changes in muscle oxygenation $(n=19,25 \%)$, arterial blood flow $(n=11,14 \%)$ and venous blood flow $(n=2,3 \%)$.

The vast majority of studies $(n=53)$ reported no effect of compression on heart rate $[2,5,7-9,13-15,27,35,47,49$, 50, 52, 56, 64, 87, 92, 94, 97, 99-108, 114, 115, 117, 123, $124,126,127,131,135,136,148,156,162,163,165,171$, 177-183], while 12 studies [22, 31, 36, 119, 122, 132, 133, $164,173,175,176,184]$ reported positive effects of compression, and three studies [14, 166, 185] reported negative effects. Blood pressure was largely not influenced by compression, with seven studies [106, 107, 123, 156, 162, 165, $186]$ reporting no change and only two studies [122, 173] reporting a positive effect. There is some evidence to suggest compression garments positively influence cardiac output, with three studies [106, 173, 176] reporting positive effects of compression and two studies reporting no effect $[15,156]$. For stroke volume, three studies $[15,106,156]$ reported no effect of compression, while only one study [173] reported a positive effect of compression. No studies reported negative effects of compression on blood pressure, cardiac output or stroke volume. Compression literature investigating changes in mean arterial pressure $[109,176,178,183]$ and total vascular conductance [176] has reported no effect of compression. Additionally, there is mixed evidence on the effects of compression garments on other cardiovascular measures. For instance, positive effects of compression have been reported on heart rate variability [173, 174], total peripheral resistance [173], electrocardiography [175] and baroreflex sensitivity [173]. However, other studies measuring heart rate variability [13], total peripheral resistance [106] and electrocardiography [165, 175] have reported no effect of compression.

Muscle oxygenation, often used to reflect changes in peripheral blood flow, was largely not influenced by compression, with ten studies $[15,22,49,56,100,104,107$, $108,127,187]$ reporting no change and seven studies [9, $104,122,133,136,156,188]$ reporting a positive effect. In addition, two studies $[35,186]$ reported negative effects of compression on muscle oxygenation. Of the 11 studies investigating arterial blood flow, six studies [22, 104, 106, $162,176,178,184]$ reported positive effects of compression, while three studies $[107,109,156]$ reported no effect and one study [189] reported a negative effect of compression. Research is limited in the effects of compression on venous blood flow with only two studies available to date, with conflicting findings of positive [107] and no effects [190] of compression reported. As alterations in peripheral blood flow (i.e. muscle and venous blood flow) are proposed to be a major contributor to the effectiveness of compression for exercise performance and recovery, future research should incorporate these measures to help assert the underlying mechanisms of compression.

\subsection{Cardiorespiratory}

Thirty-seven studies investigated cardiorespiratory outcomes related to compression garments (refer to Table S5 of the ESM). The majority of studies involved running $(n=23$, 62\%) $[7,12,17,28,47,52,64,102,115,119,127,132$, $133,135,143,145,147,162,164,166,177,180,181]$ or cycling $(n=10,27 \%)[5,22,100,109,123,165,171,178$, $183,185]$ as the primary form of exercise. However, activities relating to alpine skiing (i.e. double-poling and holding a tuck position) [15, 35], kayaking $(n=1,3 \%)$ [49] and speed skating $(n=1,3 \%)$ [108] were also investigated. Additionally, there were a range of different tests that were used to induce changes in cardiorespiratory responses whilst wearing compression garments. These involved tests to exhaustion $(n=7,19 \%)[12,28,132,133,135,165,181]$, tests that were sub-maximal $(n=15,41 \%)[7,35,52,64,119,143$, $145,147,162,164,171,178,180,183,185]$, and distance or time trials $(n=9,24 \%)[15,17,22,47,102,108,115,123$, 127]. Furthermore, six studies [5, 49, 100, 109, 166, 177] used a combination of tests (e.g. a sub-maximal test followed by a maximal test). Finally, 28 studies assessed the effects of compression garments compared to a control in cardiorespiratory changes, while 11 studies directly compared the effects of different types of compression garments. 
Of the 37 studies that investigated the effects of cardiorespiratory responses when wearing compression garments, 29 demonstrated non-significant or trivial responses $[5,7$, $12,15,17,22,28,35,47,49,64,100,102,108,109,115$, $119,123,127,135,143,147,162,165,171,178,180,181$, $183]$, two potentially negative outcomes [166, 185], while six studies [52, 132, 133, 145, 164, 177] suggested positive improvements. From these six studies, it was demonstrated that improved running economy may occur at low submaximal intensities (e.g. $8-10 \mathrm{~km} / \mathrm{h}$ ) but not necessarily at higher intensities [133, 177]. Furthermore, during downhill running, there may be small reductions in the respiratory exchange ratio of trail runners [52]. While the majority of studies found little change in the respiratory exchange ratio, it is feasible that changes may be individualised and related to gait variability [145]. Additionally, while changes in cardiorespiratory measures may not change, improvements in performance may occur [5]. Finally, it should be noted that in hot (i.e. $40^{\circ} \mathrm{C}$ ) temperatures, upper-body compression garments can increase respiratory strain, which may have ramifications on subsequent recovery $[166,185]$. Considering the current literature, it is likely that compression garments, irrespective of coverage area or pressure, do not substantially alter cardiorespiratory measures. However, future research may wish to consider individualised responses to their use and whether subsequent alterations in movement strategy as a consequence of their implementation [35] may change cardiorespiratory outcomes.

\subsection{Muscle Damage and Swelling}

Twenty-five studies have investigated the effect of compression on muscle swelling and other measures of non-blood marker muscle damage (Table S6 of the ESM). The most common measures investigated were changes in muscle circumference, thickness or volume $(n=20,80 \%)$, with no effect of compression reported in 13 studies [38, 43, 62, $64,66,77,80,88,95,120,150,163,187]$, five studies [71, $84,97,110,122]$ reporting positive effects and two studies $[90,111]$ demonstrating conflicting outcomes when using compression garments. No studies reported negative effects on muscle circumference or volume. There is evidence to suggest compression garments positively influence muscle damage, with methods including magnetic resonance imaging [161, 191], P-magnetic resonance spectra [192] and histological markers of muscle damage [193] reporting positive effects of compression. Other studies including the use of Doppler echo intensity [60], muscle pennation angle [111] and magnetic resonance imaging [150] report no effect of compression on muscle damage. Future research is encouraged to use more advanced techniques (i.e. magnetic resonance imaging, histological markers) to determine the effect of compression garments on muscle damage and standardise muscle damaging protocols so that direct comparisons can be improved. In addition, research is required to identify if an optimal duration of compression use post-exercise exists to elicit positive effects on muscle damage.

\subsection{Thermoregulation}

Nineteen studies have investigated thermoregulatory outcomes in response to the use of compression garments during, or following, exercise (Table S7 of the ESM). Exercise included running $(n=6,32 \%)$ [40, 107, 115, 166, 180, 194], cycling $(n=8,42 \%)$ [14, 106, 123, 171, 178, 183-185], a half ironman $(n=1,5 \%)$ [93] and motorised treadmill crosscountry skiing $(n=1,5 \%)$ [36]. Additionally, two studies $[39,50]$ completed a range of exercises (i.e. sprinting, jumping, cycling and throwing) and a single study [63] completed drop jumps until fatigue. Only one of the studies that have investigated thermoregulatory responses and compression garments have used professional athletes (Olympic and international medallists [36]), with all other participants being non-professional. However, one study did investigate male older adults (mean age $66 \pm 2$ years) [183]. Finally, studies investigated the effects of compression garments on skin $(n=13,68 \%)[39,40,50,63,106,107,115,171,178$, $180,183,184,194]$, and core [measured through rectal, tympanic, intestine, and oesophageal temperatures] $(n=11$, $58 \%$ ) temperature $[14,93,106,107,115,166,171,178,183$, $185,194]$, and thermal comfort and sensation $(n=1)$ [36].

Findings demonstrate that compression garments increase skin temperature at the point of coverage [106, 184], although these changes do not influence core body temperature [166, 178], sweat rate [123, 178, 183] or body mass loss [40, 93, 115, 194]. The use of compression garments increases skin temperature faster than control conditions during warm-ups [39], and these temperatures are maintained to a greater extent throughout, and following, exercise [40, 50, 63, 106, 107, 115, 180, 184]. However, athletes may not perceive differences in temperature compared to loose fitting garments [36]. At cold (i.e. $10^{\circ} \mathrm{C}$ ) environmental temperatures, compression garments may promote greater skin temperatures, although there is conflicting evidence in hot $\left(32-40{ }^{\circ} \mathrm{C}\right)$ environmental temperatures [14, $185,194]$, while sweat wicking compression garments may improve heat reduction following exercise [171]. Finally, it is unlikely that differing full-body compression garment brands, which exert similar pressure, exhibit different thermal effects during high-intensity intermittent exercise [50]. Future research may wish to investigate whether changes in pressure or textile influence thermoregulatory responses at rest, during, and following exercise. 


\subsection{Perceptual Measures}

Ninety-nine studies investigated the effects of compression garments on perceptual measures (Table S8 of the ESM). Studies used both non-professional and professional athletes. The most common measures investigated were muscle soreness $(n=51,52 \%)$ and RPE $(n=46,47 \%)$. A smaller number of studies investigated perceived fatigue $(n=13,13 \%)$, perceived recovery $(n=7,7 \%)$, muscle pain $(n=9,9 \%)$ and thermal sensation $(n=5,5 \%)$.

Of the 50 studies investigating muscle soreness, 29 reported positive effects of compression on soreness [2, 10, $11,27,31,38,40,44,50,52,65-67,69,73,79,85,86,89$, $94,99,105,110,122,126,160,167,168,182]$, while 22 reported no effect $[7,12,43,53,60,62,69,77,80,88,90$, $94,104,110,114,115,119,120,125,128,150,192,195]$. Rating of perceived exertion was largely not influenced by compression, with 40 studies reporting no change $[2,8,9$, 12-15, 47, 49, 50, 56, 69, 94, 95, 97, 99, 101-103, 106-110, $113,115,119,124,127,131,132,148,152,161,162,165$, $177,181,183$ ] and only eight studies reporting improved perception of effort while wearing compression garments [29, 30, 114, 117, 191, 194, 195]. No studies reported negative effects on muscle soreness or RPE.

Consistent with the above findings, of the nine studies investigating muscle pain, six reported a reduction $[81,84$, $95,103,104,124]$, two reported no effect of compression $[33,70]$ and one reported increased perception of pain when wearing compression garments during a 56-km ultramarathon [111]. Perceived fatigue was not influenced by wearing compression garments in eight of 13 studies [104, 110, $119,120,139,179,180,195]$, while five studies reported improved perceptions of fatigue [10, 29, 44, 122, 126]. Perceived recovery as measured by a visual analogue scale, Total Quality of Recovery Scale or Acute Recovery and Stress Scale was not influenced by compression in six of nine studies [17, 96, 97, 110, 129, 131] and improved in only three of nine studies $[29,61,94]$. Additionally, Profile of Mood States (POMS) [37], perception of performance [121], and perception of muscle oscillation were altered in a single study [196]. Finally, perceived thermal sensation was not affected by wearing compression garments in three of five studies $[101,106,107]$ and reduced in two studies where upper-body compression was worn while exercising in the heat $[14,183]$. Considering these findings, wearing compression garments may positively influence muscle soreness and muscle pain in the days following exercise. Furthermore, compression likely has little effect on RPE, perceived fatigue, perceived recovery and thermal sensation. These findings suggest it is highly unlikely that wearing compression garments will negatively influence perceptions of effort, recovery, fatigue, and soreness.

\subsubsection{Gaps in the Literature and Future Recommendations}

There is considerable breadth in the exercise and compression garment research, and this review has identified several gaps in the current knowledge. First, despite the strength of evidence that is currently available surrounding compression garments' influence on sensorimotor systems, the mechanisms and individual responses to their use are still unknown. Second, considering the substantial reduction in muscle oscillation in response to garment use, the implications of this finding have scarcely been investigated. Of note, whether there is a reduction in metabolic cost during exercise is still unknown. Third, while compression garments have demonstrated sufficient evidence to suggest a potential reduction in perceived soreness and pain following exercise, the types of exercise that this is most beneficial for has not been considered. With equivocal outcomes, it is feasible that garment use may have particular benefits following certain forms of exercise. Fourth, with compelling evidence demonstrating compression garments increase localised skin temperature, further research is still required to elucidate the influence of this across a range of environmental conditions. Fifth, while acute responses are commonly assessed, the long-term effects of compression garments are still unknown across all research areas. While acute changes often imply adaptive outcomes or chronic changes, until this research is performed, their long-term effects remain undetermined. Finally, the compression literature to date has had a particular emphasis on the lower body with $>80 \%$ using garments that are worn below the waist. Consequently, future research may wish to place greater emphasis on the differing effects of coverage area during, and in response to, exercise.

To improve research quality and transparency, and to enhance research dissemination, several recommendations can be made. First, participant belief in the garment being tested should be assessed and reported. Furthermore, a placebo condition should be implemented where possible. Research has indicated that an athlete's prior belief in the ability for compression garments to aid performance may enhance the observed outcome [2,17]. Thus, to truly quantify the expected benefit of these ergogenic aids, it is important to assess their perceived utility [110]. Second, with the potential for garment material and pressure to alter the response to exercise, all compression garment research is recommended to measure and report the pressure across multiple sites and state the material used. This can be further enhanced by aiming for targeted levels of compression at each site to account for differences in individual anthropometry. Last, because of the often subtle effects of these garments, appropriate statistical methods that consider power and the likely observed effect must be completed prior to investigation. Over $90 \%$ of the literature within this review did not state this fundamental methodological consideration 
and, as a consequence, a large portion of the literature is likely underpowered and provides findings that do not allow confident conclusions to be drawn.

\section{Conclusions}

This scoping review has identified 183 studies that have investigated the effects of compression garments on exercise-related outcomes, with a marked increase in research in recent years. The majority of research originates from Australia and has been performed in non-professional male adults. Across the eight identified topics, performance and muscle function measures have been the most investigated, followed by perceptual, and blood and salivary outcomes. While there is a lack of evidence to suggest that compression garments alter kinetic and kinematic outputs, changes in muscle oscillatory properties likely occur with their use. Furthermore, biomechanical and neuromuscular responses are largely unchanged but improvements in joint proprioception and repositioning may occur due to enhanced filtering of 'non-specific' sensory information. Despite the lack of consistent and clear evidence supporting compression garment use on cardiovascular, cardiorespiratory, and muscle damage and swelling measures, it should be noted that compression garments can increase skin temperature at the point of coverage, improve heat maintenance during and following exercise, and improve perceptions of muscle soreness and pain in the days following exercise. Finally, the majority of studies reported no ergogenic effect of compression garments on jump, time trial/race performance, strength, sprinting, or agility. Additionally, sport-specific outcomes (e.g. distance covered during competition) have been equivocal. However, it should also be noted that the research to date does not suggest that compression garments have a negative effect on performance. Therefore, athlete preference, belief, environmental considerations, and ergonomics may be the deciding factors whether they are worn during competition.

While the breadth of research that considers compression garments is considerable and this is often accompanied by conflicting findings, there are clear recommendations and directions that researchers should follow to enhance future research. First, researchers must be conscious that the effectiveness of compression garments is likely influenced by wearer belief and this should be assessed and reported. Second, pressure ranges that account for heterogeneity in anthropometry should be provided and these should be provided at multiple sites to support the standardisation of garment use. Additionally, garment material and blends should be reported with the average pressure exerted at each site. Finally, future research should continue to assess whether compression garments have an augmented effect during different forms of exercise and with different coverage areas, assess whether long-term use can alter adaptive outcomes, assess the individual responses associated with garment use and consider their use across a greater breadth of environmental conditions.

Supplementary Information The online version contains supplementary material available at https://doi.org/10.1007/s40279-021-01604-9.

\section{Declarations}

Funding At no point was funding received by any of the authors for the writing of this manuscript. The publishing of this article open access has been made possible by the UK Read and Publish (Springer Compact) agreement.

Conflicts of Interest/Competing Interests Jonathon Weakley, James Broatch, Shane O'Riordan, Matthew Morrison, Nirav Maniar and Shona Halson have no conflicts of interest.

Ethics Approval Not applicable.

Consent to Participate Not applicable.

Consent for Publication Not applicable.

Availability of Data and Material All data and material reported in this systematic review are from peer-reviewed publications.

Code Availability Not applicable.

Authors' Contributions Jonathon Weakley, Shona Halson and James Broatch conceptualised the review and criteria. Jonathon Weakley, Matthew Morrison and Shane O'Riordan completed the screening and data extraction of all data within this manuscript. All authors created the tables and figures. All authors contributed to the writing of the manuscript. All authors reviewed, refined and approved the final manuscript.

Open Access This article is licensed under a Creative Commons Attribution 4.0 International License, which permits use, sharing, adaptation, distribution and reproduction in any medium or format, as long as you give appropriate credit to the original author(s) and the source, provide a link to the Creative Commons licence, and indicate if changes were made. The images or other third party material in this article are included in the article's Creative Commons licence, unless indicated otherwise in a credit line to the material. If material is not included in the article's Creative Commons licence and your intended use is not permitted by statutory regulation or exceeds the permitted use, you will need to obtain permission directly from the copyright holder. To view a copy of this licence, visit http://creativecommons.org/licenses/by/4.0/.

\section{References}

1. Lee DC, Ali A, Sheridan S, Chan DK, Wong SH. Wearing compression garment enhances central hemodynamics? A systematic review and meta-analysis. J Strength Cond Res. 2020. https://doi. org/10.1519/JSC.0000000000003801 (Epub ahead of print).

2. Gimenes SV, Marocolo M, Pavin LN, Spigolon LMP, Barbosa Neto O, Da Silva BVC, et al. Compression stockings used during two soccer matches improve perceived muscle soreness and 
high-intensity performance. J Strength Cond Res. 2019. https:// doi.org/10.1519/JSC.0000000000003048 (Epub ahead of print).

3. Baum JT, Carter RP, Neufeld EV, Dolezal BA. Donning a novel lower-limb restrictive compression garment during training augments muscle power and strength. Int J Exerc Sci. 2020;13(3):890-9.

4. Négyesi J, Zhang LY, Jin RN, Hortobágyi T, Nagatomi R. A below-knee compression garment reduces fatigue-induced strength loss but not knee joint position sense errors. Eur J Appl Physiol. 2020;121(1):219-29. https://doi.org/10.1007/ s00421-020-04507-1.

5. Williams ER, Mckendry J, Morgan PT, Breen L. Enhanced cycling time-trial performance during multiday exercise with higher-pressure compression garment wear. Int J Sports Physiol Perform. 2020;16(2):287-95. https://doi.org/10.1123/ijspp. 2019-0716.

6. Macrae BA, Laing RM, Partsch H. General considerations for compression garments in sports: applied pressures and body coverage, in compression garments in sports: athletic performance and recovery. Berlin: Springer; 2016.

7. Ali A, Creasy RH, Edge JA. Physiological effects of wearing graduated compression stockings during running. Eur $\mathbf{J}$ Appl Physiol. 2010;109(6):1017-25. https://doi.org/10.1007/ s00421-010-1447-1.

8. Armstrong SA, Till ES, Maloney SR, Harris GA. Compression socks and functional recovery following marathon running: a randomized controlled trial. J Strength Cond Res. 2015;29(2):52833. https://doi.org/10.1519/jsc.0000000000000649.

9. Menetrier A, Mourot L, Bouhaddi M, Regnard J, Tordi N. Compression sleeves increase tissue oxygen saturation but not running performance. Int J Sports Med. 2011;32(11):864-8. https://doi. org/10.1055/s-0031-1283181.

10. Atkins R, Lam WK, Scanlan AT, Beaven CM, Driller M. Lowerbody compression garments worn following exercise improves perceived recovery but not subsequent performance in basketball athletes. J Sports Sci. 2020;38(9):961-9. https://doi.org/10.1080/ 02640414.2020.1737387.

11. Ferguson RA, Dodd MJ, Paley VR. Neuromuscular electrical stimulation via the peroneal nerve is superior to graduated compression socks in reducing perceived muscle soreness following intense intermittent endurance exercise. Eur J Appl Physiol. 2014;114(10):2223-32. https://doi.org/10.1007/ s00421-014-2943-5.

12. Sperlich B, Haegele M, Achtzehn S, Linville J, Holmberg $\mathrm{H}-\mathrm{C}$, Mester J. Different types of compression clothing do not increase sub-maximal and maximal endurance performance in well-trained athletes. J Sports Sci. 2010;28(6):609-14. https:// doi.org/10.1080/02640410903582768

13. Leicht AS, Ahmadian M, Nakamura FY. Influence of lower body compression garments on cardiovascular autonomic responses prior to, during and following submaximal cycling exercise. Eur J Appl Physiol. 2020;120(7):1601-7. https://doi.org/10.1007/ s00421-020-04391-9.

14. Leoz-Abaurrea I, Aguado-Jiménez R. Upper body compression garment: physiological effects while cycling in a hot environment. Wilderness Environ Med. 2017;28(2):94-100. https://doi. org/10.1016/j.wem.2017.02.005.

15. Sperlich B, Born DP, Zinner C, Hauser A, Holmberg HC. Does upper-body compression improve $3 \times 3$-min double-poling sprint performance? Int J Sports Physiol Perform. 2014;9(1):48-57. https://doi.org/10.1123/ijspp.2013-0137.

16. Angelakos I, Mills C, O'Halloran J. The effects of compression garments on stability and lower limb kinematics during a forward lunge. J Hum Kinet. 2020. https://doi.org/10.2478/ hukin-2019-0074.
17. Brophy-Williams N, Driller MW, Kitic CM, Fell JW, Halson SL. Wearing compression socks during exercise aids subsequent performance. J Sci Med Sport. 2019;22(1):123-7. https://doi.org/ 10.1016/j.jsams.2018.06.010.

18. Da Silva CA, Helal L, Da Silva RP, Belli KC, Umpierre D, Stein R. Association of lower limb compression garments during high-intensity exercise with performance and physiological responses: a systematic review and meta-analysis. Sports Med. 2018;48(8):1859-73. https://doi.org/10.1007/ s40279-018-0927-z.

19. Engel FA, Holmberg HC, Sperlich B. Is there evidence that runners can benefit from wearing compression clothing? Sports Med. 2016;46(12):1939-52. https://doi.org/10.1007/ s40279-016-0546-5.

20. Marques-Jimenez D, Calleja-Gonzalez J, Arratibel I, Delextrat A, Terrados N. Are compression garments effective for the recovery of exercise-induced muscle damage? A systematic review with meta-analysis. Physiol Behav. 2016. https://doi.org/10.1016/j. physbeh.2015.10.027.

21. Hill J, Howatson G, Van Someren K, Leeder J, Pedlar C. Compression garments and recovery from exercise-induced muscle damage: a meta-analysis. Br J Sports Med. 2014;48(18):1340-6. https://doi.org/10.1136/bjsports-2013-092456.

22. Broatch JR, Bishop DJ, Halson S. Lower limb sports compression garments improve muscle blood flow and exercise performance during repeated-sprint cycling. Int J Sports Physiol Perform. 2018;13(7):882-90. https://doi.org/10.1123/ijspp.2017-0638.

23. Tricco AC, Lillie E, Zarin W, O'brien KK, Colquhoun H, Levac $\mathrm{D}$, et al. PRISMA extension for scoping reviews (PRISMA-ScR): checklist and explanation. Ann Intern Med. 2018;169(7):467-73. https://doi.org/10.7326/m18-0850.

24. Cole AK, Mcgrath ML, Harrington SE, Padua DA, Rucinski TJ, Prentice WE. Scapular bracing and alteration of posture and muscle activity in overhead athletes with poor posture. J Athl Train. 2013;48(1):12-24. https://doi.org/10.4085/1062-6050-48.1.13.

25. Whitehead S, Weakley J, Cormack S, Alfano H, Kerss J, Mooney $\mathrm{M}$, et al. The applied sports science and medicine of netball: a systematic scoping review. Sports Med. 2021;51(8):1715-931.

26. Griffin SA, Perera NKP, Murray A, Hartley C, Fawkner SG, Kemp $S$, et al. The relationships between rugby union, and health and well-being: a scoping review. Br J Sports Med. 2021;55(6):319. https://doi.org/10.1136/bjsports-2020-102085.

27. Bieuzen F, Brisswalter J, Easthope C, Vercruyssen F, Bernard $\mathrm{T}$, Hausswirth C. Effect of wearing compression stockings on recovery after mild exercise-induced muscle damage. Int J Sports Physiol Perform. 2014;9(2):256-64. https://doi.org/10.1123/ ijspp.2013-0126.

28. Berry MJ, Mcmurray RG. Effects of graduated compression stockings on blood lactate following an exhaustive bout of exercise. Am J Phys Med. 1987;66(3):121-32.

29. Bahnert A, Norton K, Lock P. Association between post-game recovery protocols, physical and perceived recovery, and performance in elite Australian Football League players. J Sci Med Sport. 2013;16(2):151-6. https://doi.org/10.1016/j.jsams.2012. 05.008 .

30. Beaven CM, Cook C, Gray D, Downes P, Murphy I, Drawer $\mathrm{S}$, et al. Electrostimulation's enhancement of recovery during a rugby preseason. Int J Sports Physiol Perform. 2013;8(1):92-8. https://doi.org/10.1123/ijspp.8.1.92.

31. Duffield R, Murphy A, Kellett A, Reid M. Recovery from repeated on-court tennis sessions: combining cold-water immersion, compression, and sleep recovery interventions. Int J Sports Physiol Perform. 2014;9(2):273-82. https://doi.org/10.1123/ ijspp.2012-0359. 
32. Gill ND, Beaven CM, Cook C. Effectiveness of post-match recovery strategies in rugby players. Br J Sports Med. 2006;40(3):2603. https://doi.org/10.1136/bjsm.2005.022483.

33. Govus AD, Andersson EP, Shannon OM, Provis H, Karlsson M, Mcgawley K. Commercially available compression garments or electrical stimulation do not enhance recovery following a sprint competition in elite cross-country skiers. Eur J Sport Sci. 2018;18(10):1299-308. https://doi.org/10.1080/17461391.2018. 1484521.

34. Mcmaster DT, Beaven CM, Mayo B, Gill N, Hébert-Losier K. The efficacy of wrestling-style compression suits to improve maximum isometric force and movement velocity in well-trained male rugby athletes. Front Physiol. 2017;8:874. https://doi.org/ 10.3389/fphys.2017.00874.

35. Sperlich B, Born D-P, Swarén M, Kilian Y, Geesmann B, KohlBareis $\mathrm{M}$, et al. Is leg compression beneficial for alpine skiers? Sports Med Arthrosc Rehabil Ther Technol. 2013;5(1):18. https://doi.org/10.1186/2052-1847-5-18.

36. Toolis T, Mcgawley K. The effect of compression garments on performance in elite winter biathletes. Int J Sports Physiol Perform. 2020;16(1):145-8. https://doi.org/10.1123/ijspp. 2019-0790.

37. Choi Y, Makita M, Nakamura Y, Yamamoto K, Nara T, Kawamura $\mathrm{T}$, et al. Effect of novel recovery garments utilising nanodiamond- and nanoplatinum-coated materials (DPV576-C) on physical and psychological stress in baseball players: a randomised, placebo-controlled trial. Eur J Sport Sci. 2019;19(7):869-75. https://doi.org/10.1080/17461391.2018.1544279.

38. Davies V, Thompson KG, Cooper SM. The effects of compression garments on recovery. J Strength Cond Res. 2009;23(6):1786-94. https://doi.org/10.1519/JSC.0b013e3181b42589.

39. Doan BK, Kwon YH, Newton RU, Shim J, Popper EM, Rogers RA, et al. Evaluation of a lower-body compression garment. J Sports Sci. 2003;21(8):601-10. https://doi.org/10.1080/02640 41031000101971.

40. Duffield R, Edge J, Merrells R, Hawke E, Barnes M, Simcock $\mathrm{D}$, et al. The effects of compression garments on intermittent exercise performance and recovery on consecutive days. Int $\mathbf{J}$ Sports Physiol Perf. 2008;3(4):454-68. https://doi.org/10.1123/ ijspp.3.4.454.

41. Erten YT, Sahinkaya T, Dinc E, Kilinc BE, Bayraktar B, Kurtoglu M. The effects of compression garments and electrostimulation on athletes' muscle soreness and recovery. J Exerc Rehabil. 2016;12(4):308-13. https://doi.org/10.12965/jer.1632632.316.

42. Hasan H, Davids K, Chow JY, Kerr G. Compression and texture in socks enhance football kicking performance. Hum Mov Sci. 2016. https://doi.org/10.1016/j.humov.2016.04.008.

43. Montgomery PG, Pyne DB, Cox AJ, Hopkins WG, Minahan CL, Hunt PH. Muscle damage, inflammation, and recovery interventions during a 3-day basketball tournament. Eur J Sport Sci. 2008;8(5):241-50. https://doi.org/10.1080/17461390802251844.

44. Montgomery PG, Pyne DB, Hopkins WG, Dorman JC, Cook $\mathrm{K}$, Minahan CL. The effect of recovery strategies on physical performance and cumulative fatigue in competitive basketball. $\mathrm{J}$ Sports Sci. 2008;26(11):1135-45. https://doi.org/10.1080/02640 410802104912.

45. Tsuruike M, Ellenbecker TS. Effects of a compression garment on shoulder external rotation force outputs during isotonic contractions. J Strength Cond Res. 2013;27(2):519-25. https://doi. org/10.1519/JSC.0b013e3182578145.

46. Zamporri J, Aguinaldo A. The effects of a compression garment on lower body kinematics and kinetics during a drop vertical jump in female collegiate athletes. Orthop J Sports Med. 2018;6(8):2325967118789955. https://doi.org/10.1177/23259 67118789955 .
47. Rider BC, Coughlin AM, Hew-Butler TD, Goslin BR. Effect of compression stockings on physiological responses and running performance in division III collegiate cross-country runners during a maximal treadmill test. J Strength Cond Res. 2014;28(6):1732-8. https://doi.org/10.1519/JSC.0000000000 000287.

48. Lee H, Hong K, Lee Y. Compression pants with differential pressurization: kinetic and kinematical effects on stability. Text Res J. 2016;87(13):1554-64. https://doi.org/10.1177/0040517516 657056 .

49. Dascombe B, Laursen P, Nosaka K, Polglaze T. No effect of upper body compression garments in elite flat-water kayakers. Eur J Sport Sci. 2013;13(4):341-9. https://doi.org/10.1080/17461 391.2011 .606842$.

50. Duffield R, Portus M. Comparison of three types of full-body compression garments on throwing and repeat-sprint performance in cricket players. Br J Sports Med. 2007;41(7):409-14. https://doi.org/10.1136/bjsm.2006.033753.

51. Sperlich B, Born DP, Swaren M, Kilian Y, Geesmann B, KohlBareis M, et al. Is leg compression beneficial for alpine skiers? BMC Sports Sci Med Rehabil. 2013;5(1):18. https://doi.org/10. 1186/2052-1847-5-18

52. Ehrstrom S, Gruet M, Giandolini M, Chapuis S, Morin JB, Vercruyssen F. Acute and delayed neuromuscular alterations induced by downhill running in trained trail runners: beneficial effects of high-pressure compression garments. Front Physiol. 2018;9:1627. https://doi.org/10.3389/fphys.2018.01627.

53. Pearce AJ, Kidgell DJ, Grikepelis LA, Carlson JS. Wearing a sports compression garment on the performance of visuomotor tracking following eccentric exercise: a pilot study. J Sci Med Sport. 2009;12(4):500-2. https://doi.org/10.1016/j.jsams.2008. 06.002 .

54. Fu W, Liu Y, Zhang S, Xiong X, Wei S. Effects of local elastic compression on muscle strength, electromyographic, and mechanomyographic responses in the lower extremity. J Electromyogr Kinesiol. 2012;22(1):44-50. https://doi.org/10.1016/j.jelekin. 2011.10.005.

55. Chaudhari AMW, Jamison ST, Mcnally MP, Pan X, Schmitt LC. Hip adductor activations during run-to-cut manoeuvres in compression shorts: implications for return to sport after groin injury. J Sports Sci. 2014;32(14):1333-40. https://doi.org/10. 1080/02640414.2014.889849.

56. Vercruyssen F, Easthope C, Bernard T, Hausswirth C, Bieuzen $\mathrm{F}$, Gruet $\mathrm{M}$, et al. The influence of wearing compression stockings on performance indicators and physiological responses following a prolonged trail running exercise. Eur J Sport Sci. 2014;14(2):144-50. https://doi.org/10.1080/17461391.2012. 730062.

57. Martorelli SS, Martorelli AS, Pereira MC, Rocha-Junior VA, Tan JG, Alvarenga JG, et al. Graduated compression sleeves: effects on metabolic removal and neuromuscular performance. $\mathrm{J}$ Strength Cond Res. 2015;29(5):1273-8. https://doi.org/10.1519/ jsc.0000000000000401.

58. Maton B, Thiney G, Dang S, Tra S, Bassez S, Wicart P, et al. Human muscle fatigue and elastic compressive stockings. Eur J Appl Physiol. 2006;97(4):432-42. https://doi.org/10.1007/ s00421-006-0187-8.

59. Miyamoto N, Hirata K, Mitsukawa N, Yanai T, Kawakami Y. Effect of pressure intensity of graduated elastic compression stocking on muscle fatigue following calf-raise exercise. J Electromyogr Kinesiol. 2011;21(2):249-54. https://doi.org/10.1016/j. jelekin.2010.08.006.

60. Pereira MC, Bottaro M, Brown LE, Rocha-Junior VA, Martorelli SS, Nóbrega OT, et al. Do compression sleeves worn during exercise affect muscle recovery? Isokinet Exerc Sci. 2014;22(4):26571. https://doi.org/10.3233/IES-140537. 
61. Hill JA, Howatson G, Van Someren KA, Walshe I, Pedlar CR. Influence of compression garments on recovery after marathon running. J Strength Cond Res. 2014;28(8):2228-35. https://doi. org/10.1519/JSC.0000000000000469.

62. Cerqueira MS, Santos Borges L, Dos Santos Rocha JA, Brito Andrade H, Silva Pirôpo U, Lupato Conrado LA, et al. Twelve hours of a compression sleeve is not enough to improve the muscle recovery of an exercise-damaged upper arm. Apunts Sports Med. 2015;50(185):23-8. https://doi.org/10.1016/j.apunts.2014. 07.003 .

63. Sambaher N, Aboodarda SJ, Silvey DB, Button DC, Behm DG. Effect of an ankle compression garment on fatigue and performance. J Strength Cond Res. 2016;30(2):326-35. https://doi.org/ 10.1519/JSC.0000000000001011.

64. Mizuno S, Arai M, Todoko F, Yamada E, Goto K. Wearing compression tights on the thigh during prolonged running attenuated exercise-induced increase in muscle damage marker in nlood. Front Physiol. 2017;8:834. https://doi.org/10.3389/fphys.2017. 00834.

65. Upton CM, Brown FCW, Hill JA. Efficacy of compression garments on recovery from a simulated rugby protocol. J Strength Cond Res. 2017;31(11):2977-82. https://doi.org/10.1519/JSC. 0000000000002145 .

66. Goto K, Morishima T. Compression garment promotes muscular strength recovery after resistance exercise. Med Sci Sports Exerc. 2014;46(12):2265-70. https://doi.org/10.1249/mss.0000000000 000359 .

67. Kim J, Kim J, Lee J. Effect of compression garments on delayedonset muscle soreness and blood inflammatory markers after eccentric exercise: a randomized controlled trial. J Exerc Rehabil. 2017;13(5):541-5. https://doi.org/10.12965/jer.1735088.554.

68. Shimokochi Y, Kuwano S, Yamaguchi T, Abutani H, Shima N. Effects of wearing a compression garment during night sleep on recovery from high-intensity eccentric-concentric quadriceps muscle fatigue. J Strength Cond Res. 2017;31(10):2816-24. https://doi.org/10.1519/jsc.0000000000002116.

69. Hill J, Howatson G, Van Someren K, Gaze D, Legg H, Lineham J, et al. The effects of compression-garment pressure on recovery after strenuous exercise. Int J Sports Physiol Perform. 2017;12(8):1078-84. https://doi.org/10.1123/ijspp.2016-0380.

70. Ravier G, Bouzigon R, Beliard S, Tordi N, Grappe F. Benefits of compression garments worn during handball-specific circuit on short-term fatigue in professional players. J Strength Cond Res. 2018;32(12):3519-27. https://doi.org/10.1519/jsc.0000000000 001342.

71. Brown F, Jeffries O, Gissane C, Howatson G, Van Someren K, Pedlar C, et al. Custom-fitted compression garments enhance recovery from muscle damage in rugby players. J Strength Cond Res. 2020. https://doi.org/10.1519/jsc.0000000000003408 (Epub ahead of print).

72. Struhár I, Kumstát M, Králová DM. Effect of compression garments on physiological responses after uphill running. J Hum Kinet. 2018;61:119-29. https://doi.org/10.1515/ hukin-2017-0136.

73. Kraemer WJ, Hooper DR, Kupchak BR, Saenz C, Brown LE, Vingren JL, et al. The effects of a roundtrip trans-American jet travel on physiological stress, neuromuscular performance, and recovery. J Appl Physiol. 2016;121(2):438-48. https://doi.org/ 10.1152/japplphysiol.00429.2016.

74. Pereira MC, Bottaro M, Brown LE, Rocha-Junior VA, Martorelli SS, Neumann M, et al. The effects of graduated compression sleeves on muscle performance: a randomised controlled trial. Int J Sports Sci Coach. 2014;9(5):985-92. https://doi.org/10.1260/ 1747-9541.9.5.985.

75. Zhang S, Fu W, Xia R, Wang X. Compression apparel does not have an acute effect on quadriceps strength but is associated with changes in muscle activation patterns. Isokinet Exerc Sci. 2016;24(1):59-65. https://doi.org/10.3233/IES-150601.

76. Wang X, Xia R, Fu W. Reduced muscle activity during isokinetic contractions associated with external leg compression. Technol Health Care. 2016;24:S533-9. https://doi.org/10.3233/ THC-161179.

77. Carling J, Francis K, Lorish C. The effects of continuous external compression on delayed-onset muscle soreness (DOMS). Int J Rehabil Health. 1995;1(4):223-5. https://doi.org/10.1007/BF022 14641.

78. Kraemer WJ, Bush JA, Triplett-Mcbride NT, Koziris LP, Mangino LC, Fry AC, et al. Compression garments: influence on muscle fatigue. J Strength Cond Res. 1998;12(4):211-5.

79. Jakeman JR, Byrne C, Eston RG. Efficacy of lower limb compression and combined treatment of manual massage and lower limb compression on symptoms of exercise-induced muscle damage in women. J Strength Cond Res. 2010;24(11):3157-65. https://doi.org/10.1519/JSC.0b013e3181e4f80c.

80. Terbizan DJ, Barry AM, Stone KA, Talaski JL, Bennett T, Hackney KJ. Compression garments do not improve recovery from plyometric exercise. Missouri J Health Phys Ed Rec Dance. 2018;28(Special Issue):1-11.

81. Mcdonnell AC, Cooper D, Mlinar T, Mekjavic IB. The effect of post-exercise application of either graduated or uniform compression socks on the mitigation of delayed onset muscle soreness. Text Res J. 2019;89(9):1792-806. https://doi.org/10.1177/ 0040517518780002.

82. Choi J, Hong K. Compression suits with and without films and their effects on EMG during isokinetic exercise. Fash Text. 2019;6(1):1-14. https://doi.org/10.1186/s40691-019-0176-2.

83. Kraemer WJ, Bush JA, Wickham RB, Denegar CR, Gomez AL, Gotshalk LA, et al. Continuous compression as an effective therapeutic intervention in treating eccentric-exercise-induced muscle soreness. J Sport Rehabil. 2001;10(1):11-23. https://doi. org/10.1123/jsr.10.1.11.

84. Kraemer WJ, Bush JA, Wickham RB, Denegar CR, Gomez AL, Gotshalk LA, et al. Influence of compression therapy on symptoms following soft tissue injury from maximal eccentric exercise. J Orthop Sports Phys Ther. 2001;31(6):282-90. https://doi. org/10.2519/jospt.2001.31.6.282.

85. Jakeman JR, Byrne C, Eston RG. Lower limb compression garment improves recovery from exercise-induced muscle damage in young, active females. Eur J App Physiol. 2010;109(6):113744. https://doi.org/10.1007/s00421-010-1464-0.

86. Hettchen M, Glöckler K, Von Stengel S, Piechele A, Lötzerich $\mathrm{H}$, Kohl M, et al. Effects of compression tights on recovery parameters after exercise induced muscle damage: a randomized controlled crossover study. Evid Based Complement Altern Med. 2019;2019(1):1-12. https://doi.org/10.1155/2019/5698460.

87. Duffield R, Cannon J, King M. The effects of compression garments on recovery of muscle performance following highintensity sprint and plyometric exercise. J Sci Med Sport. 2010;13(1):136-40. https://doi.org/10.1016/j.jsams.2008.10.006.

88. French DN, Thompson KG, Garland SW, Barnes CA, Portas MD, Hood PE, et al. The effects of contrast bathing and compression therapy on muscular performance. Med Sci Sports Exerc. 2008;40(7):1297-306. https://doi.org/10.1249/MSS.0b013e3181 $6 \mathrm{~b} 10 \mathrm{~d} 5$.

89. Goto K, Mizuno S, Mori A. Efficacy of wearing compression garments during post-exercise period after two repeated bouts of strenuous exercise: a randomized crossover design in healthy, active males. Sports Med Open. 2017;3(1):25. https://doi.org/10. 1186/s40798-017-0092-1.

90. Kraemer WJ, Flanagan SD, Comstock BA, Fragala MS, Earp JE, Dunn-Lewis C, et al. Effects of a whole body compression garment on markers of recovery after a heavy resistance workout 
in men and women. J Strength Cond Res. 2010;24(3):804-14. https://doi.org/10.1519/JSC.0b013e3181d33025.

91. Kraemer WJ, Bush JA, Bauer JA, Tripleft-Mcbride N, Paxton NJ, Clemson A, et al. Influence of compression garments on vertical jump performance in NCAA division I volleyball players. $\mathrm{J}$ Strength Cond Res. 1996;10(3):180-3.

92. Higgins T, Naughton GA, Burgess D. Effects of wearing compression garments on physiological and performance measures in a simulated game-specific circuit for netball. J Sci Med Sport. 2009;12(1):223-6. https://doi.org/10.1016/j.jsams.2007.08.018.

93. Del Coso J, Areces F, Salinero JJ, González-Millán C, AbiánVicén J, Soriano L, et al. Compression stockings do not improve muscular performance during a half-ironman triathlon race. Eur J Appl Physiol. 2014;114(3):587-95. https://doi.org/10.1007/ s00421-013-2789-2.

94. Pruscino CL, Halson S, Hargreaves M. Effects of compression garments on recovery following intermittent exercise. Eur $\mathbf{J}$ Appl Physiol. 2013;113(6):1585-96. https://doi.org/10.1007/ s00421-012-2576-5.

95. Areces F, Salinero JJ, Abian-Vicen J, Gonzalez-Millan C, RuizVicente D, Lara B, et al. The use of compression stockings during a marathon competition to reduce exercise-induced muscle damage: are they really useful? J Orthop Sports Phys Ther. 2015;45(6):462-70. https://doi.org/10.2519/jospt.2015.5863.

96. Zinner C, Pelka M, Ferrauti A, Meyer T, Pfeiffer M, Sperlich B. Responses of low and high compression during recovery after repeated sprint training in well-trained handball players. Eur $\mathbf{J}$ Sport Sci. 2017;17(10):1304-10. https://doi.org/10.1080/17461 391.2017.1380707.

97. Marqués-Jiménez D, Calleja-González J, Arratibel-Imaz I, Delextrat A, Uriarte F, Terrados N. Influence of different types of compression garments on exercise-induced muscle damage markers after a soccer match. Res Sports Med. 2018;26(1):2742. https://doi.org/10.1080/15438627.2017.1393755.

98. Willems ME, Webb EC. Effects of wearing graduated compression garment during eccentric exercise. Medicina Sportiva. 2010;14(4):193-8.

99. Ali A, Caine MP, Snow BG. Graduated compression stockings: physiological and perceptual responses during and after exercise. J Sports Sci. 2007;25(4):413-9. https://doi.org/10.1080/02640 410600718376.

100. Scanlan AT, Dascombe BJ, Reaburn PR, Osborne M. The effects of wearing lower-body compression garments during endurance cycling. Int J Sports Physiol Perform. 2008;3(4):424-38. https:// doi.org/10.1123/ijspp.3.4.424.

101. Barwood MJ, Corbett J, Feeney J, Hannaford P, Henderson D, Jones I, et al. Compression garments: no enhancement of highintensity exercise in hot radiant conditions. Int J Sports Physiol Perform. 2013;8(5):527-35. https://doi.org/10.1123/ijspp.8.5. 527.

102. Vercruyssen F, Gruet M, Colson SS, Ehrstrom S, Brisswalter J. Compression garments, muscle contractile function, and economy in trail runners. Int J Sports Physiol Perform. 2017;12(1):62-8. https://doi.org/10.1123/ijspp.2016-0035.

103. Ali A, Creasy RH, Edge JA. The effect of graduated compression stockings on running performance. J Strength Cond Res. 2011;25(5):1385-92. https://doi.org/10.1519/JSC.0b013e3181 d6848e.

104. Kerhervé HA, Samozino P, Descombe F, Pinay M, Millet GY, Pasqualini M, et al. Calf compression sleeves change biomechanics but not performance and physiological responses in trail running. Front Physiol. 2017;8(247):1-13. https://doi.org/10.3389/ fphys.2017.00247.

105. Treseler C, Bixby WR, Nepocatych S. The effect of compression stockings on physiological and psychological responses after 5 -km performance in recreationally active females. J Strength
Cond Res. 2016;30(7):1985-91. https://doi.org/10.1519/jsc. 0000000000001291

106. Macrae BA, Laing RM, Niven BE, Cotter JD. Pressure and coverage effects of sporting compression garments on cardiovascular function, thermoregulatory function, and exercise performance. Eur J Appl Physiol. 2012;112(5):1783-95. https://doi.org/10. 1007/s00421-011-2146-2.

107. Venckunas T, Trinkunas E, Kamandulis S, Poderys J, Grunovas A, Brazaitis M. Effect of lower body compression garments on hemodynamics in response to running session. Sci World J. 2014;2014(1):1-10. https://doi.org/10.1155/2014/353040.

108. Born D-P, Zinner C, Herlitz B, Richter K, Holmberg H-C, Sperlich B. Muscle oxygenation asymmetry in ice speed skaters: not compensated by compression. Int J Sports Physiol Perform. 2014;9(1):58. https://doi.org/10.1123/ijspp.2012-0210.

109. Smale BA, Northey JM, Smee DJ, Versey NG, Rattray B. Compression garments and cerebral blood flow: influence on cognitive and exercise performance. Eur J Sport Sci. 2018;18(3):31522. https://doi.org/10.1080/17461391.2017.1413139.

110. Brophy-Williams N, Driller MW, Kitic CM, Fell JW, Halson SL. Effect of compression socks worn between repeated maximal running bouts. Int J Sports Physiol Perform. 2017;12(5):621-7. https://doi.org/10.1123/ijspp.2016-0162.

111. Geldenhuys AG, Swart J, Bosch A. Investigation of the impact of below-knee compression garments on markers of exerciseinduced muscle damage and performance in endurance runners: a prospective randomized controlled trial. Sports Health. 2019;11(3):254-64. https://doi.org/10.1177/1941738119837644.

112. Zadow EK, Edwards KH, Kitic CM, Fell JW, Adams MJ, Singh I, et al. Compression socks reduce running-induced intestinal damage. J Strength Cond Res. 2020. https://doi.org/10.1519/jsc. 0000000000003870.

113. Burden RJ, Glaister M. The effects of ionized and nonionized compression garments on sprint and endurance cycling. J Strength Cond Res. 2012;26(10):2837-43. https://doi.org/10. 1519/JSC.0b013e318241e155.

114. Faulkner JA, Gleadon D, Mclaren J, Jakeman JR. Effect of lower-limb compression clothing on 400-m sprint performance. J Strength Cond Res. 2013;27(3):669-76. https://doi.org/10.1519/ JSC.0b013e31825c2f50.

115. Houghton LA, Dawson B, Maloney SK. Effects of wearing compression garments on thermoregulation during simulated team sport activity in temperate environmental conditions. J Sci Med Sport. 2009;12(2):303-9. https://doi.org/10.1016/j.jsams.2007. 09.004 .

116. Kumstát M, Struhár I, Hlinský T, Thomas A. Effects of immediate post-exercise recovery after a high intensity exercise on subsequent cycling performance. J Hum Sport Exerc. 2018;14(2):399-412. https://doi.org/10.14198/jhse.2019.142.12.

117. Rugg S, Sternlicht E. The effect of graduated compression tights, compared with running shorts, on counter movement jump performance before and after submaximal running. J Strength Cond Res. 2013;27(4):1067-73. https://doi.org/10.1519/JSC.0b013 e3182610956.

118. Wannop JW, Worobets JT, Madden R, Stefanyshyn DJ. Influence of compression and stiffness apparel on vertical jump performance. J Strength Cond Res. 2016;30(4):1093-101. https://doi. org/10.1519/jsc.0000000000001195.

119. Mizuno S, Arai M, Todoko F, Yamada E, Goto K. Wearing lowerbody compression garment with medium pressure impaired exercise-induced performance decrement during prolonged running. PLoS ONE. 2017;12(5): e0178620. https://doi.org/10.1371/journ al.pone. 0178620 .

120. Mizuno S, Morii I, Tsuchiya Y, Goto K. Wearing compression garment after endurance exercise promotes recovery of exercise performance. Int J Sports Med. 2016;37(11):870-7. 
121. Kraemer WJ, Bush JA, Newton RU, Duncan ND, Volek JS, Denegar CR, et al. Influence of a compression garment on repetitive power output production before and after different types of muscle fatigue. Sports Med Train Rehabil. 1998;8(2):163-84. https:// doi.org/10.1080/15438629809512525.

122. Broatch JR, Bishop DJ, Zadow EK, Halson S. Effects of sports compression socks on performance, physiological, and hematological alterations after long-haul air travel in elite female volleyballers. J Strength Cond Res. 2019;33(2):492-501. https://doi. org/10.1519/JSC.0000000000003002.

123. De Glanville KM, Hamlin MJ. Positive effect of lower body compression garments on subsequent $40-\mathrm{kM}$ cycling time trial performance. J Strength Cond Res. 2012;26(2):480-6. https:// doi.org/10.1519/JSC.0b013e318225ff61.

124. Chatard JC, Atlaoui D, Farjanel J, Louisy F, Rastel D, Guézennec CY. Elastic stockings, performance and leg pain recovery in 63-year-old sportsmen. Eur J Appl Physiol. 2004;93(3):347-52. https://doi.org/10.1007/s00421-004-1163-9.

125. Driller MW, Halson SL. The effects of wearing lower body compression garments during a cycling performance test. Int J Sports Physiol Perform. 2013;8(3):300-6. https://doi.org/10. 1123/ijspp.8.3.300.

126. Hamlin MJ, Mitchell CJ, Ward FD, Draper N, Shearman JP, Kimber NE. Effect of compression garments on short-term recovery of repeated sprint and 3-km running performance in rugby union players. J Strength Cond Res. 2012;26(11):2975-82. https://doi. org/10.1519/JSC.0b013e3182711e0b.

127. Born DP, Holmberg HC, Goernert F, Sperlich B. A novel compression garment with adhesive silicone stripes improves repeated sprint performance-a multi-experimental approach on the underlying mechanisms. BMC Sports Sci Med Rehabil. 2014;6:21. https://doi.org/10.1186/2052-1847-6-21.

128. Ballmann C, Hotchkiss H, Marshall M, Rogers R. The effect of wearing a lower body compression garment on anaerobic exercise performance in Division I NCAA basketball players. Sports. 2019;7(6):144. https://doi.org/10.3390/sports7060144.

129. Argus CK, Driller MW, Ebert TR, Martin DT, Halson SL. The effects of 4 different recovery strategies on repeat sprint-cycling performance. Int J Sports Physiol Perform. 2013;8(5):542-8. https://doi.org/10.1123/ijspp.8.5.542.

130. Lee H, Kim K, Lee Y. The effect of the pressure level of sports compression pants on dexterity and movement-related cortical potentials. Sci Sports. 2017;32(5):e183-90. https://doi.org/10. 1016/j.scispo.2017.03.006.

131. Pavin LN, Leicht AS, Gimenes SV, Da Silva BVC, Simim MaDM, Marocolo M, et al. Can compression stockings reduce the degree of soccer match-induced fatigue in females? Res Sports Med. 2019;27(3):351-64. https://doi.org/10.1080/15438 627.2018 .1527335 .

132. Varela-Sanz A, Espana J, Carr N, Boullosa DA, Esteve-Lanao J. Effects of gradual-elastic compression stockings on running economy, kinematics, and performance in runners. J Strength Cond Res. 2011;25(10):2902-10. https://doi.org/10.1519/JSC. 0b013e31820f5049.

133. Dascombe BJ, Hoare TK, Sear JA, Reaburn PR, Scanlan AT. The effects of wearing undersized lower-body compression garments on endurance running performance. Int J Sports Physiol Perform. 2011;6(2):160-73.

134. Goh SS, Laursen PB, Dascombe B, Nosaka K. Effect of lower body compression garments on submaximal and maximal running performance in cold (10 degrees $\mathrm{C}$ ) and hot (32 degrees $\mathrm{C})$ environments. Eur J Appl Physiol. 2011;111(5):819-26. https:// doi.org/10.1007/s00421-010-1705-2.

135. Kemmler W, Von Stengel S, Kockritz C, Mayhew J, Wassermann A, Zapf J. Effect of compression stockings on running performance in men runners. J Strength Cond Res. 2009;23(1):101-5. https://doi.org/10.1519/JSC.0b013e3181 8 eaef3.

136. Sear JA, Hoare TK, Scanlan AT, Abt GA, Dascombe BJ. The effects of whole-body compression garments on prolonged high-intensity intermittent exercise. J Strength Cond Res. 2010;24(7):1901-10. https://doi.org/10.1519/JSC.0b013e3181 $\mathrm{db} 251 \mathrm{~b}$.

137. Gupta A, Bryers JJ, Clothier PJ. The effect of leg compression garments on the mechanical characteristics and performance of single-leg hopping in healthy male volunteers. BMC Sports Sci Med Rehabil. 2015;7(1):10. https://doi.org/10.1186/ s13102-015-0005-x.

138. Michael JS, Dogramaci SN, Steel KA, Graham KS. What is the effect of compression garments on a balance task in female athletes? Gait Posture. 2014;39(2):804-9. https://doi.org/10.1016/j. gaitpost.2013.11.001.

139. Lucas-Cuevas AG, Priego Quesada JI, Gimenez JV, Aparicio I, Cortell-Tormo JM, Perez-Soriano P. Can graduated compressive stockings reduce muscle activity during running? Res Q Exerc Sport. 2017;88(2):223-9. https://doi.org/10.1080/02701 367.2017.1294726.

140. Cavanaugh MT, Quigley PJ, Hodgson DD, Reid JC, Behm DG. Kinesiology tape or compression sleeve applied to the thigh does not improve balance or muscle activation before or following fatigue. J Strength Cond Res. 2016;30(7):1992-2200. https://doi. org/10.1519/JSC.0000000000001297.

141. De Britto MA, Lemos AL, Dos Santos CS, Stefanyshyn DJ, Carpes FP. Effect of a compressive garment on kinematics of jump-landing tasks. J Strength Cond Res. 2017;31(9):2480-8. https://doi.org/10.1519/jsc.0000000000001620.

142. Kurz E, Anders C. Effects of wearing lower leg compression sleeves on locomotion economy. J Sports Sci. 2018;36(18):210510. https://doi.org/10.1080/02640414.2018.1439355.

143. Broatch JR, Brophy-Williams N, Phillips EJ, O'bryan SJ, Halson SL, Barnes S, et al. Compression garments reduce muscle movement and activation during submaximal running. Med Sci Sports Exerc. 2020;52(3):685-95. https://doi.org/10.1249/mss. 0000000000002182.

144. Broatch JR, Halson SL, Panchuk D, Bishop DJ, Waddington G. Compression enhances lower-limb somatosensation in individuals with poor somatosensation, but impairs performance in individuals wth good somatosensation. Transl Sports Med. 2020;4(2):280-8. https://doi.org/10.1002/tsm2.214.

145. Stickford AS, Chapman RF, Johnston JD, Stager JM. Lower-leg compression, running mechanics, and economy in trained distance runners. Int J Sports Physiol Perform. 2015;10(1):76-83. https://doi.org/10.1123/ijspp.2014-0003.

146. Moreno-Pérez D, Marín PJ, López-Samanes Á, Cejuela R, Esteve-Lanao J. Muscle activation in middle-distance athletes with compression stockings. Sensors. 2020;20(5):1-8. https:// doi.org/10.3390/s20051268.

147. Cheng L, Xiong C. The effects of compression stockings on the energetics and biomechanics during walking. Eur J Appl Physiol. 2019;119(11-12):2701-10. https://doi.org/10.1007/ s00421-019-04245-z.

148. Hintzy F, Gregoire N, Samozino P, Chiementin X, Bertucci W, Rossi J. Effect of thigh-compression shorts on muscle activity and soft-tissue vibration during cycling. J Strength Cond Res. 2019;33(8):2145-52. https://doi.org/10.1519/JSC.0000000000 002402 .

149. Bernhardt T, Anderson GS. Influence of moderate prophylactic compression on sport performance. J Strength Cond Res. 2005;19(2):292-7. https://doi.org/10.1519/1533-4287(2005) 19[292:IOMPCO]2.0.CO;2. 
150. Heiss R, Hotfiel T, Kellermann M, May MS, Wuest W, Janka $\mathrm{R}$, et al. Effect of compression garments on the development of edema and soreness in delayed-onset muscle soreness (DOMS). J Sports Sci Med. 2018;17(3):392-401.

151. Mills C, Knight J, Milligan G. Do ergogenic aids alter lower extremity joint alignment during a functional movement lunge prior to and following an exercise bout? J Hum Kinet. 2015;45:917. https://doi.org/10.1515/hukin-2015-0002.

152. Lucas-Cuevas AG, Priego-Quesada JI, Aparicio I, Giménez JV, Llana-Belloch S, Pérez-Soriano P. Effect of 3 weeks use of compression garments on stride and impact shock during a fatiguing run. Int J Sports Med. 2015;36(10):826-31. https://doi.org/10. 1055/s-0035-1548813.

153. Song SJ, Beard CA, Ustinova KI. The effects of wearing a compression top on trunk and golf club motions during golf swing. Cloth Text Res J. 2015;34(1):48-60. https://doi.org/10.1177/ $0887302 X 15602096$.

154. Kuster MS, Grob K, Kuster M, Wood GA, Gächter A. The benefits of wearing a compression sleeve after ACL reconstruction. Med Sci Sports Exerc. 1999;31(3):368-71. https://doi.org/10. 1097/00005768-199903000-00003.

155. Barss TS, Pearcey GEP, Munro B, Bishop JL, Zehr EP. Effects of a compression garment on sensory feedback transmission in the human upper limb. J Neurophysiol. 2018;120(1):186-95. https:// doi.org/10.1152/jn.00581.2017.

156. Book J, Prince CN, Villar R, Hughson RL, Peterson SD. Investigating the impact of passive external lower limb compression on central and peripheral hemodynamics during exercise. Eur J Appl Physiol. 2016;116(4):717-27. https://doi.org/10.1007/ s00421-016-3331-0.

157. Ghai S, Driller MW, Masters RSW. The influence of below-knee compression garments on knee-joint proprioception. Gait Posture. 2018;60:258-61. https://doi.org/10.1016/j.gaitpost.2016.08. 008 .

158. Zhang LY, Négyesi J, Okuyama T, Tanaka M, Hortobágyi T, Nagatomi R. Position of compression garment around the knee affects healthy adults' knee joint position sense acuity. Hum Move Sci. 2019;67(1):1-9. https://doi.org/10.1016/j.humov. 2019.102519.

159. Mancini S, Mariani F, Rossi A, Cioncoloni D, Ginanneschi F. Effects of elastic stockings on peripheral and central nervous system. Int Angiol. 2020;39(2):155-60. https://doi.org/10.23736/ s0392-9590.20.04223-6.

160. Perrey S, Bringard A, Racinais S, Puchaux K, Belluye N, Estivalet $\mathrm{M}$, et al. Graduated compression stockings and delayed onset muscle soreness. In: Estivalet M, Brisson P, editors, The engineering of sport. Paris: Springer; 2008. p. 547-54.

161. Miyamoto N, Kawakami Y. No graduated pressure profile in compression stockings still reduces muscle fatigue. Int J Sports Med. 2015;36(3):220-5. https://doi.org/10.1055/s-0034-13904 95.

162. Okamoto T, Sakamaki-Sunaga M, Min S, Miura T, Iwasaki T. Acute effect of brisk walking with graduated compression stockings on vascular endothelial function and oxidative stress. Clin Physiol Funct Imaging. 2013;33(6):455-62. https://doi.org/10. 1111/cpf.12052.

163. Driller MW, Halson SL. The effects of lower-body compression garments on recovery between exercise bouts in highly-trained cyclists. J Sci Cycl. 2013;2(1):45-50.

164. Lovell DI, Mason DG, Delphinus EM, Mclellan CP. Do compression garments enhance the active recovery process after highintensity running? J Strength Cond Res. 2011;25(12):3264-8. https://doi.org/10.1519/JSC.0b013e31821764f8.

165. Rimaud D, Messonnier L, Castells J, Devillard X, Calmels P. Effects of compression stockings during exercise and recovery on blood lactate kinetics. Eur J Appl Physiol. 2010;110(2):425-33. https://doi.org/10.1007/s00421-010-1503-x.

166. Leoz-Abaurrea I, Santos-Concejero J, Grobler L, Engelbrecht L, Aguado-Jiménez R. Running performance while wearing a heat dissipating compression garment in male recreational runners. J Strength Cond Res. 2016;30(12):3367-72. https://doi.org/10. 1519/jsc.0000000000001467.

167. Marqués-Jiménez D, Calleja-González J, Arratibel I, Delextrat A, Uriarte F, Terrados N. Physiological and physical responses to wearing compression garments during soccer matches and recovery. J Sports Med Phys Fit. 2018;58(11):1642-51. https:// doi.org/10.23736/s0022-4707.17.07831-8.

168. Martínez-Navarro I, Aparicio I, Priego-Quesada JI, Pérez-Soriano P, Collado E, Hernando B, et al. Effects of wearing a full body compression garment during recovery from an ultra-trail race. Eur J Sport Sci. 2020. https://doi.org/10.1080/17461391. 2020.1783369 (Epub ahead of print).

169. Zaleski AL, Ballard KD, Pescatello LS, Panza GA, Kupchak BR, Dada MR, et al. The effect of compression socks worn during a marathon on hemostatic balance. Phys Sportsmed. 2015;43(4):336-41. https://doi.org/10.1080/00913847.2015. 1072456.

170. Kupchak BR, Kraemer WJ, Hooper DR, Saenz C, Dulkis LL, Secola PJ, et al. The effects of a transcontinental flight on markers of coagulation and fibrinolysis in healthy men after vigorous physical activity. Chronobiol Int. 2017;34(2):148-61. https://doi. org/10.1080/07420528.2016.1247851.

171. Leoz-Abaurrea I, Tam N, Aguado-Jiménez R. Heat dissipating upper body compression garment: thermoregulatory, cardiovascular, and perceptual responses. J Sport Health Sci. 2019;8(5):450-6. https://doi.org/10.1016/j.jshs.2016.01.008.

172. Taylor BA, Zaleski AL, Ballard KD, Panza GA, Fernandez AB, Corso L, et al. Compression socks worn during flight and hemostatic balance in boston marathon runners on oral contraceptives. Clin J Sport Med. 2018;28(3):278-83. https://doi.org/10.1097/ jsm.0000000000000452.

173. Piras A, Gatta G. Evaluation of the effectiveness of compression garments on autonomic nervous system recovery after exercise. J Strength Cond Res. 2017;31(6):1636-43. https://doi.org/10. 1519/jsc.0000000000001621.

174. Hu J, Browne JD, Baum JT, Robinson A, Arnold MT, Reid $\mathrm{SP}$, et al. Lower limb graduated compression garments modulate autonomic nervous system and improve post-training recovery measured via heart rate variability. Int J Exerc Sci. 2020;13(7):1794-806.

175. Nguyen LTN, Eager D, Nguyen H. The relationship between compression garments and electrocardiogram signals during exercise and recovery phase. Biomed Eng Online. 2019;18(1):27-36. https://doi.org/10.1186/s12938-019-0645-2.

176. Dorey T, O'Brien M, Robinson S, Kimmerly D. Knee-high compression socks minimize head-up tilt-induced cerebral and cardiovascular responses following dynamic exercise. Scand J Med Sci Sports. 2018;28(7):1766-74. https://doi.org/10.1111/ sms.13084.

177. Bringard A, Perrey S, Belluye N. Aerobic energy cost and sensation responses during submaximal running exercise-positive effects of wearing compression tights. Int J Sports Med. 2006;27(05):373-8. https://doi.org/10.1055/s-2005-865718.

178. Fujii N, Nikawa T, Tsuji B, Kenny GP, Kondo N, Nishiyasu T. Wearing graduated compression stockings augments cutaneous vasodilation but not sweating during exercise in the heat. Physiol Rep. 2017;5(9): e13252. https://doi.org/10.14814/phy2.13252.

179. Priego JI, Lucas-Cuevas AG, Aparicio I, Giménez JV, CortellTormo JM, Pérez-Soriano P. Long-term effects of graduated compression stockings on cardiorespiratory performance. Biol 
Sport. 2015;32(3):219-23. https://doi.org/10.5604/20831862. 1150304.

180. Quesada JIP, Lucas-Cuevas AG, Gil-Calvo M, Giménez JV, Aparicio I, De Anda RMCO, et al. Effects of graduated compression stockings on skin temperature after running. J Therm Biol. 2015;52:130-6. https://doi.org/10.1016/j.jtherbio.2015.06.005.

181. Rivas E, Smith JD, Sherman NW. Leg compressions improve ventilatory efficiency while reducing peak and post exercise blood lactate, but does not improve perceived exertion, exercise economy or aerobic exercise capacity in endurance-trained runners. Respir Physiol Neurobiol. 2017;237(1):1-6. https://doi.org/ 10.1016/j.resp.2016.12.003.

182. Webb E, Willems M. Effects of wearing graduated compression garment during eccentric exercise. Med Sport. 2010;14(4):1938. https://doi.org/10.2478/v10036-010-0031-4.

183. Leoz-Abaurrea I, Izquierdo M, Gonzalez-Izal M, Aguado-Jiménez R. Increased thermoregulatory strain when wearing an upper body compression garment during moderate exercise in trained older adults. J Aging Phys Act. 2017;25(1):134-9. https://doi. org/10.1123/japa.2016-0106.

184. Ménétrier A, Mourot L, Degano B, Bouhaddi M, Walther G, Regnard J, et al. Effects of three postexercice recovery treatments on femoral artery blood flow kinetics. J Sports Med Phys Fit. 2015;55(4):258-66.

185. Leoz-Abaurrea I, Tam N, Aguado JR. Impaired cardiorespiratory responses when wearing an upper body compression garment during recovery in a hot environment $\left(40^{\circ} \mathrm{C}\right)$. J Sports Med Phys Fit. 2016;56(6):684-91.

186. Rennerfelt K, Lindorsson S, Brisby H, Baranto A, Zhang Q. Effects of exercise compression stockings on anterior muscle compartment pressure and oxygenation during running: a randomized crossover trial conducted in healthy recreational runners. Sports Med. 2019;49(9):1465-73. https://doi.org/10.1007/ s40279-019-01103-y.

187. Coza A, Dunn JF, Anderson B, Nigg BM. Effects of compression on muscle tissue oxygenation at the onset of exercise. $\mathrm{J}$ Strength Cond Res. 2012;26(6):1631-7. https://doi.org/10.1519/ JSC.0b013e318254885b.
188. Boucourt B, Bouhaddi M, Mourot L, Tordi N, Menetrier A. Changes in tissue oxygen saturation with calf compression sleeve: before, during and after a cycling exercise. J Sports Med Phys Fit. 2015;55(12):1497-501.

189. Sperlich B, Born DP, Kaskinoro K, Kalliokoski KK, Laaksonen MS. Squeezing the muscle: compression clothing and muscle metabolism during recovery from high intensity exercise. PLoS ONE. 2013;8(4): e60923. https://doi.org/10.1371/journal.pone. 0060923.

190. Oficial-Casado F, Aparicio I, Julian-Rochina I, Blanes M, PerezSoriano P. Effects of a fatiguing run in popliteal vein flow using sports compression socks. J Ind Text. 2020;49(7):967-78. https:// doi.org/10.1177/1528083718804202.

191. Miyamoto N, Kawakami Y. Effect of pressure intensity of compression short-tight on fatigue of thigh muscles. Med Sci Sports Exerc. 2014;46(11):2168-74. https://doi.org/10.1249/MSS. 0000000000000330 .

192. Trenell MI, Rooney KB, Sue CM, Thomspon CH. Compression garments and recovery from eccentric exercise: a (31)P-MRS study. J Sports Sci Med. 2006;5(1):106-14.

193. Valle X, Til L, Drobnic F, Turmo A, Montoro JB, Valero O, et al. Compression garments to prevent delayed onset muscle soreness in soccer players. Muscles Ligaments Tendons J. 2013;3(4):295-302.

194. Goh SS, Laursen PB, Dascombe B, Nosaka K. Effect of lower body compression garments on submaximal and maximal running performance in cold $\left(10^{\circ} \mathrm{C}\right)$ and hot $\left(32^{\circ} \mathrm{C}\right)$ environments. Eur J Appl Physiol. 2011;111(5):819-26. https://doi.org/10.1007/ s00421-010-1705-2.

195. Mizuno S, Arai M, Todoko F, Yamada E, Goto K. Wearing compression tights on the thigh during prolonged running attenuated exercise-induced increase in muscle damage marker in blood. Front Physiol. 2017;8:834. https://doi.org/10.3389/fphys.2017. 00834.

196. Li YN, Lu AM, Dai XQ, Chen JA, Zhao XW. Effect of garment pressure on lower limb muscle activity during running. Advan Mater Res. 2011;175:832-6. https://doi.org/10.4028/www.scien tific.net/AMR.175-176.832.

\section{Authors and Affiliations}

\section{Jonathon Weakley ${ }^{1,2,3}$ (1) James Broatch ${ }^{4} \cdot$ Shane O'Riordan $^{4,5} \cdot$ Matthew Morrison $^{1} \cdot$ Nirav Maniar $^{2,6}$. Shona L. Halson ${ }^{1,2}$}

1 School of Behavioural and Health Sciences, Australian Catholic University, 1100 Nudgee Rd, Banyo, Brisbane, QLD, Australia

2 Sports Performance, Recovery, Injury and New Technologies (SPRINT) Research Centre, Australian Catholic University, Fitzroy, VIC, Australia

3 Carnegie Applied Rugby Research (CARR) Centre, Institute for Sport, Physical Activity and Leisure, Leeds Beckett University, Leeds, West Yorkshire, UK
4 Institute for Health and Sport (iHeS), Victoria University, Footscray, VIC, Australia

5 Australia Institute of Sport, Bruce, ACT, Australia

6 School of Behavioural and Health Sciences, Australian Catholic University, Fitzroy, Melbourne, VIC, Australia 